


\title{
Mental health around pregnancy and child development from early childhood to adolescence
}

\author{
Stephanie von Hinke* $\quad$ Nigel Rice ${ }^{\dagger} \quad$ Emma Tominey ${ }^{\ddagger}$
}

This version: August 7, 2019

\begin{abstract}
We identify the causal effect of mothers' mental health during early - and soon after pregnancy on a range of child psychological, socio-emotional and cognitive outcomes measured between ages 4-16. Results suggest a negative effect on children's psychological and socio-emotional skills in early childhood, but these effects fade-out between the ages of 11-13. We find no significant effect on cognitive outcomes. The fade-out of effects may be partly explained by compensatory behaviour of parents, as we find that mental health during or soon after pregnancy raises breastfeeding and improves measures of interaction between mother and child.
\end{abstract}

Keywords: Prenatal psychological health; child psychological outcomes; child socioemotional outcomes; child cognitive outcomes; ALSPAC

JEL classification: I12, I14, I3

Acknowledgements: We are extremely grateful to all the families who took part in this study, the midwives for their help in recruiting them, and the whole ALSPAC team, which includes interviewers, computer and laboratory technicians, clerical workers, research scientists, volunteers, managers, receptionists and nurses. Ethical approval for the study was obtained from the ALSPAC Ethics and Law Committee and the Local Research Ethics Committees. Informed consent for the use of data collected via questionnaires and clinics was obtained from participants following the recommendations of the ALSPAC Ethics and Law Committee at the time. The UK Medical Research Council and Wellcome (Grant ref: 102215/2/13/2) and the University of Bristol provide core support for ALSPAC. This publication is the work of the authors, who serve as guarantors for the contents of this paper. A comprehensive list of grants funding is available on the ALSPAC website (http://www.bristol.ac.uk/alspac/external/documents/grant-acknowledgements.pdf); This research was specifically funded by the UK Department for Education and Skills (Grant ref: EOR/SBU/2002/121). We thank seminar participants of the Centre for Health Economics, University of York; Manchester Centre for Health Economics, University of Manchester; and the European Society of Population Economics, 2019, University of Bath for helpful comments.

\footnotetext{
${ }^{*}$ School of Economics, University of Bristol, UK; Erasmus School of Economics, Erasmus University Rotterdam, The Netherlands; and Institute for Fiscal Studies, UK. S.vonHinke@bristol.ac.uk

${ }^{\dagger}$ Centre for Health Economics, Department of Economics and Related Studies, University of York, UK. Nigel.Rice@york.ac.uk

${ }^{\ddagger}$ Department of Economics and Related Studies, University of York, UK, HCEO, IZA. Emma.Tominey@york.ac.uk
} 


\section{Introduction}

It is well-known that shocks to health that occur in utero or early in life can have lasting impacts on later-life outcomes (see for example the reviews in Almond and Currie, 2011a, 2011b; Currie et al., 2010). Such evidence points to the importance of public policies such as health care provision (e.g., medical intervention for low birth weight babies; Bharadwaj, Loken and Neilson, 2013) as well as the importance of parental investments (e.g., breastfeeding; Del Bono and Rabe, 2012) in determining a child's future outcomes, including health, cognitive skills, socio-emotional skills, educational attainment and income.

The majority of studies that consider the effects of in utero shocks focus primarily on the mother's (or child's) physical health. ${ }^{1}$ There is, however, a sparsity of evidence on the impact of maternal mental health during pregnancy on later life outcomes of children. ${ }^{2}$ There exist at least two reasons for such a lack of evidence. First, since the vast majority of observational studies only include information on mothers following child birth, maternal mental health is generally only observed after (as opposed to during) pregnancy. Second, maternal mental health is endogenous to child behaviours and outcomes, and locating plausibly exogenous variation is challenging. Given these two constraints, almost all studies that explore the effects of maternal mental health in utero use an Intention-To-Treat (ITT) design, estimating the effects of exogenous variation in the environment assumed to induce stress/anxiety in

\footnotetext{
${ }^{1}$ Much of this literature specifies exogenous shocks that exploit the effects of e.g. famines (Almond et al., 2010; Scholte, van den Berg, and Lindeboom, 2012), flu epidemics (Almond, 2006; Almond and Mazumder, 2005; Kelly, 2011), temperature during gestation (Bruckner et al., 2014) and exposure to radiation (Almond, Edlund and Palme, 2009; Black et al., 2013). It should not be ruled out, however, that these events may also impact on a mother's mental health.

${ }^{2}$ Poor mental health or stress around the birth of a child is very common: one in five mothers experience clinical depressive symptoms during pregnancy (Marcus et al 2003) whilst postpartum depression is common up to a year after birth (Sohr-Preston and Scaramella, 2006). Note that postpartum depression is different to the less severe "baby blues" which affects around $80 \%$ of mothers and tends to occur in the first 10 weeks after birth.
} 
pregnant mothers that impacts their child's later life outcomes. These events include death of a family member (Black, Devereux and Salvanes, 2016; Presson and Rossin-Slater, 2018), stress linked to terrorist attacks or armed conflicts (Mansour and Rees, 2010; Brown, 2014), natural disasters such as earthquakes or flooding (Simeonova, 2009; Currie and RossinSlater, 2013; Torche, 2011), or the 2008 financial crisis (Olafsson, 2016). A summary of the findings is that stress during pregnancy causes poor birth outcomes and childhood obesity, but there are no long-run effects on cognitive ability. However, the extent to which these shocks actually affect mental health of the pregnant mother is often unknown, since reliable data on maternal mental health during pregnancy are rarely available.

This paper estimates the causal effect of mothers' mental health around pregnancy, on a wide range of child outcomes including psychological, socio-emotional and cognitive outcomes. ${ }^{3}$ The contribution of our paper is four-fold. First, we directly observe a validated measure of psychological health for a large cohort of mothers during and shortly after pregnancy. Accordingly, we do not rely on events such as earthquakes or the death of a family member as proxies, and estimate the effect of actual changes in mental health, as opposed to the reduced form effect of the event.

Second, we measure psychological, socio-emotional and cognitive outcomes of children, from as early as 41 months after birth up to age 16, allowing us to look at a wide range of outcomes across the life cycle of child development. This is an important innovation. For example Black, Devereux and Salvanes (2016) find no long-run effect on cognitive outcomes of stress during pregnancy whilst Persson and Rossin Slater (2018) find that there are longrun effects, but on measures including drugs usage, treatment for depression and medication for attention deficit hyperactivity disorder. These results suggest that mothers' mental

\footnotetext{
${ }^{3}$ Throughout we use psychological health interchangeably with mental health. These cover the impact of stress/anxiety and depression on the well-being of a mother.
} 
health affects different aspects of child development at different points during childhood. In contrast, we observe psychological and socio-emotional outcomes between ages 7-16 and cognitive outcomes between ages 4-16, allowing us to identify the different dynamics of the maternal mental health effect across multiple dimensions of child skills.

Third, mothers' mental health around pregnancy can affect child outcomes through several pathways including i) a biological channel, via increased maternal cortisol levels and/or children's cortisol levels induced by stress and anxiety; and ii) a behavioural response of the mother, changing her investments in the child. ${ }^{4}$ An advantage of our data is that we observe a large range of potential behavioural responses of the mother during and shortly after pregnancy, including breastfeeding duration and measures of parenting quality. This allows us to examine the effect of mothers' mental health around pregnancy on a diverse set of parental investments in early childhood.

Fourth, the psychological literature on the effects of depression around pregnancy emphasizes the important of both the prenatal and postpartum periods. We explore potential differential effects by considering measures of mental health both during pregnancy but also in the period shortly after.

Since maternal mental health is endogenous to child outcomes, our identification strategy relies on a set of instrumental variables constructed from unexpected life experiences, including the illness of a friend or relative and (separately) the death of a friend or relative. ${ }^{5}$ We observe the indicators for friends' and relatives' illness or death twice: between the start of pregnancy and 18 weeks gestation, which we use to instrument maternal mental health in utero at 18 weeks gestation, and between mid-pregnancy and 8 weeks post-birth, which we

\footnotetext{
${ }^{4}$ Section 2 lays out concisely the evidence for the potential channels.

${ }^{5}$ A similar shock to mental health was adopted by Black, Devereux and Salvanes (2016) and Presson and Rossin-Slater (2018) and Le and Nguyen (2018), of grandparent/family bereavement during pregnancy.
} 
use to instrument mental health at 8 weeks post birth. The instruments strongly predict mothers' mental health. Our interpretation of their use is that they induce a shock to the mental health of mothers during and shortly after pregnancy, which may have long-term effects on child development. We provide evidence that the 'shock' is not linked to mothers' mental health prior to her pregnancy.

We explore possible violations of the exclusion restriction of our instrumental variables. For example, it is possible that mothers for whom a friend or relative was ill or died are a nonrandom group, with different socio-economic status or health habits, and these may affect child outcomes independently. In all regressions, we include a wide set of control variables measured pre-birth to capture the socio-economic status of parents and grandparents. In addition, if the illness or death of a friend or relative during pregnancy refers to a grandparent, there may be a direct effect of the IV on child outcomes through a reduction in grandparent time spent with the child. However, our estimates are statistically indistinguishable across samples that vary in the quantity of childcare provided by their grandparents when aged 15-38 months. Finally, it may be that our first stage regressions are driven by those with a pre-existing mental health issue and consequently, what we estimate is a local average treatment effect. Our results, however, persist when we only include mothers without pre-existing mental health problems, excluding those who experienced mental health problems prior to pregnancy.

Our results show two main findings. First, we find sizeable effects of maternal mental health during pregnancy on children's outcomes, including psychological and socio-emotional outcomes when the outcomes are measured early in the child's lifetime. However, the IV estimates suggest that the effects of mothers' mental health during early pregnancy (at 8 weeks post birth) fade out over time, with it being insignificantly different from zero by the 
time the child is 115 (157) months old. We find no significant effects on cognitive skills; neither in the short-run, nor in the longer-run. Second, we find behavioural responses to the incidence of mental health during pregnancy including parenting investments in the child. These behavioural responses suggest that the dissipating effects on child skills may be driven by compensatory behaviours of the mother. Specifically, in response to maternal mental health problems around birth, we find evidence of increased breastfeeding and increased interactions between the mother and child.

The structure of paper is as follows. Section 2 provides a review of the literature describing the mechanisms through which mothers' mental health during pregnancy may drive child outcomes, Section 3 describes the data and Section 4 provides details on our instrumental variables methodology. Our results in Section 5 show that mothers' mental health has a strong short-term effect on a range of child outcomes which fade-out over the longer term. We also explore results separately by child gender. Section 6 explores the robustness of the results and Section 7 investigates the behavioural response of parental investments to mothers' mental health problems around pregnancy. Section 8 concludes.

\section{Literature relating prenatal stress to child outcomes}

This section presents evidence on the channels through which maternal mental health around pregnancy may have a meaningful impact on the development of her child. A predisposition to mental health has a genetic component, so a mother's mental health may directly affect their child's psychological and socio-emotional well-being directly. During pregnancy, however, evidence also suggests a strong biological and behavioural response to maternal mental health. 
A biological mechanism exists when, during pregnancy, stress of the mother raises her levels of cortisol. Maternal cortisol has been linked to many child outcomes, including lower fetal growth and birth weight (e.g. Gitau et al., 1998). There is accumulating evidence that elevated maternal cortisol concentrations during pregnancy are associated with fetal brain anatomy. For example, Li et. al. (2011), find evidence of reduced fetal brain growth following late gestation increases in maternal serum cortisol. Other studies report intrauterine exposure to elevated cortisol leading to an increased risk of stress, social anxiety and internalizing behaviours of newborns and infants (for example, Davis et al., 2007; Davis, et al., 2011). LeWinn et al. (2009) report exposure to high levels of maternal cortisol during pregnancy leading to lowered cognitive skills in offspring.

More recent interest has focused on the particular role of the amygdala in a child's development, since this regulates a variety of emotions (including fear, depression and anxiety). It develops at an early embryonic stage, is associated with a range of neurodevelopmental and psychopathological disorders, and it is believed to be sensitive to elevated levels of cortisol. Buss et al. (2012) find that higher maternal cortisol concentrations in early gestation are associated with larger right amygdala volume in girls at 7 years, which is consistent with the suggestion that negative emotions are predominantly processed in the right hand side of the amygdala. It has also been found that exposure to high levels of stress in early postnatal life is associated with an altered and enlarged amygdala and an increase in anxiety disorders (for example, in children reared in orphanages; Tottenham, et al., 2010). Similarly, maternal postnatal depression has also been found to be associated with larger amygdala volumes in preadolescent children (Lupien et al., 2011).

In additional to any observed biological link, both pre- and post-natal maternal mental health problems may also lead to behavioural response, where mothers are less likely to seek 
prenatal care (Miller, 1992), gain less weight during pregnancy (Walker, Cooney and Riggs, 1999), use more drugs and alcohol, smoke more and feel more stressed (Zuckerman et al., 1989). These factors can independently drive later outcomes of the child, either directly via health endowments or indirectly through child investments.

\section{Data}

Our data are from a cohort of children born in one geographic area (Avon) of England. Women resident in Avon with an expected delivery date between 1st April 1991 and 31st December 1992 were invited to take part in the population-based Avon Longitudinal Study of Parents and Children (ALSPAC). The initial number of pregnancies enrolled is 14,541. Of these initial pregnancies, there was a total of 14,676 foetuses, resulting in 14,062 live births and 13,988 children who were alive at 1 year of age (ALSPAC is a cohort; there is no systematic data collection on siblings). However, as common in longitudinal surveys, attrition leads to fewer individuals being observed over time. Depending on the outcome of interest, the final sample varies but includes a maximum of 7,852 mother-child pairs.

The Avon area has approximately 1 million inhabitants and is broadly representative of the UK as a whole, although slightly more affluent than the general population (Boyd et al., 2013; Fraser et al., 2013). ${ }^{6}$

\footnotetext{
${ }^{6}$ See www.bristol.ac.uk/alspac for a more detailed description of the data. The study website contains details of all data that are available through a fully searchable data dictionary and variable search tool see http://www.bristol.ac.uk/alspac/researchers/our-data/. At age 7, an attempt was made to bolster the initial sample with eligible cases who had failed to join the study originally. As a result, when considering variables from age 7 onwards, there are data available for more than the 14,541 pregnancies mentioned above. However, this does not apply here, as our analysis requires us to observe maternal mental health around pregnancy, which is only available for those who joined the study originally.
} 


\subsection{Maternal mental health}

One advantage of the ALSPAC data is the detailed information available during pregnancy, as most other birth cohorts start data collection after the child has been born, and therefore need to rely more on retrospective data collection (von Hinke and Jones, 2015). We exploit this by specifically investigating the effect of maternal mental health measured during as well as shortly after pregnancy; at 18 weeks gestation and 8 weeks post-birth respectively. While these capture mental health at specific points in time, we do not know for how long between these points a mother has experienced problems. Accordingly, we refer to the periods covered by the two measures of mental health as the early gestation and perinatal period (referring to the period shortly before and after birth, though note that the latter may also refer to the second half of pregnancy).

Our main measure of maternal mental health is the Crown-Crisp Experimental Index (CCEI) that captures a broad definition of mental health, measuring general anxiety, depression and somatic symptoms. ${ }^{7}$ A high value of the CCEI indicates that mothers are more affected, or have worse mental health. The CCEI consists of three subscales: anxiety, depression and somaticism. Each measures specific attributes of mental health, though our main analysis uses the overall score as a more general measure of the mother's state of mental health.

In order to analyse separately the effect of early gestation and perinatal mental health on child outcomes, there must be variation within mothers in their incidence between the two points in time. The unconditional correlation between the two measures is 0.58 which, while high, suggests significant variation across time. Indeed, of mothers who do (do not)

\footnotetext{
${ }^{7}$ Our results are similar if we specify mothers' Edinburgh Post-natal Depression Score (EPDS), capturing the extent to which the mother is at risk of perinatal depression, as the measure of mental health.
} 
experience poor mental health issues during early gestation, as measured by being in the top quartile (not in the top quartile) of the distribution of mental health problems, only $59 \%$ (19\%) report poor mental health 8 weeks after giving birth. This suggests there remains substantial variation in maternal mental health within mother's pregnancies. Table 1 reports the statistics of the measure of CCEI at 18 weeks gestation and 8 weeks postpartum. The measures are standardised on the full sample for whom data are available. Hence, a negative mean indicates that mothers in the final sample had relatively better mental health during pregnancy.

In addition to the two measures of maternal mental health we observe a binary indicator that measures whether the mother ever had depression. We include this in the analyses, aiming to capture and account for a maternal baseline measure of mental health. ${ }^{8}$

\subsection{Child outcomes}

ALSPAC contains an extremely rich set of child outcomes, including psychological, socioemotional, cognitive, and behavioural outcomes. We focus on child depression measured at age 108 months, 115 months and 140 months as a measure of psychological outcomes. This is based on the short Mood and Feelings Questionnaire (Angold et al., 1995), a validated measure of depressive symptoms.

We use the Strengths and Difficulties Questionnaire (SDQ) as a measure of socio-emotional development. The SDQ is a well recognised and validated measure of child behaviour, developed as a mental health screening instrument (see Goodman, 1997). The parent is asked 20 questions in total, which are grouped into dimensions of behaviour including emotional problems, conduct problems, hyperactivity, and peer problems. We use the total score which is a

\footnotetext{
${ }^{8}$ The mean and standard deviations are provided in Table 2.
} 
composite of these four dimensions. Of particular use to our study is that SDQ is measured across a range of child ages; at 81, 115, 140, 157 and 198 months.

The child's cognitive outcomes are measured by their performance on different tests of academic achievement. First, we use an entry assessment test, taken by all pupils about to start primary school (ages $4-5$ ). Although there were no compulsory national assessment tests at this time, the Local Education Authorities covering the ALSPAC area used the same tests, which is available for $80 \%$ of (not privately owned) schools. In addition, we use four nationally set examinations taken at ages 7, 11, 14 and 16 (also known as the Key Stage 1 (KS1), Key Stage 2 (KS2), Key Stage 3 (KS3) and Key Stage 4 (KS4, or GCSE) examinations, respectively). With the exception of the age 16 test score outcomes (KS4), the examinations are low-stakes for the children as they are all entitled to progress to the next stage of schooling irrespective of the results. However, schools are judged on the performance of all test scores and consequently the test scores are high stakes to some degree for teachers and schools. KS4 is high stakes for the children also, as it determines whether the children are able to progress into higher education up to age 18.

Children's scores are obtained from the National Pupil Database, a census of all pupils in England within the state school system, which is matched into ALSPAC. For each of the Key Stage tests (1--4), we use an average score for the child's mandatory subjects. ${ }^{9}$ All child outcomes have been standardised on the full sample of children for whom data are available, with mean 0 and standard deviation 1 . Descriptive statistics are reported in Table 1.

\footnotetext{
${ }^{9}$ For KS1, this is an average of the child's reading, writing, spelling and mathematics scores; KS2 includes reading, writing, science and mathematics. For KS3 and KS4, the final score is an average of the child's English, mathematics and science.
} 


\subsection{Covariates}

We exploit the richness of the data and include a wide range of control variables, aiming to capture baseline mental health, as well as other maternal and household characteristics such as socio-economic status of the child's parents and grandparents. These are important, as they may be correlated with the measures of maternal mental health and they may independently drive child outcomes. Furthermore, they will absorb some of the unobserved residual heterogeneity that may otherwise be correlated with the instrumental variables and the child outcomes. For example, it may be that only mothers of low socio-economic status have friends or relatives who are either ill or died during pregnancy. This source of correlation is controlled for by including a quadratic in maternal age at birth, dummy variables for maternal education, the mother's mother's and mother's father's education, the mother's social class and additionally a dummy variable indicating whether the pregnancy was intentional. Finally, we account for a set of variables relating to the child, including the child's gender, their month of birth, and an indicator for being non-white.

Table 2 presents the descriptive statistics of all covariates, showing that $7.5 \%$ of mothers reported ever having had depression in the past and mothers are on average 28.8 years old at the birth of the child. The majority of mothers have achieved O-levels ${ }^{10}(46 \%)$ and are in the skilled non-manual social class (44\%); $76 \%$ of pregnancies were intentional. Furthermore, looking at the covariates relating to the children, we see that just under half of all cohort members are girls, and $3.9 \%$ are non-white.

A schematic timeline of the occurrence of key events for ALSPAC mothers and children, together with the timings of outcomes, measurement of controls and maternal mental health, is provided in Figure 1.

\footnotetext{
${ }^{10}$ These are examinations comparable to the current GCSE exams taken at age 16.
} 


\subsection{Instrumental variables}

We create two instrumental variables for each measure of mothers' mental health during and after pregnancy. The first IV is the illness of a friend or relative and the second IV is the death of a friend or relative. At 18 weeks gestation mothers provided information on whether they had been affected by a friend or relative who had died since she became pregnant. The answers included "affected a lot"; "moderately affected"; "mildly affected"; "not affected"; "did not happen." We construct a binary indicator which takes the value of 1 if the mother experienced this and 0 otherwise. Similarly, at 8 weeks post birth the mother was asked whether, since the middle of her pregnancy, she had been affected by a friend or relative who had died. We construct a binary indicator, which takes the value of 1 if the mother experienced this and 0 otherwise. At both 18 weeks gestation and 8 weeks post birth the mother was also asked about being affected by a friend or relative being ill and we use this information to construct a further two binary variables.

The incidence of a friend or relative being ill or dying between pregnancy and 18 weeks gestation are included as instrumental variables for mothers' mental health at 18 weeks gestation; whereas the set of instrumental variables for mothers' mental health at 8 weeks post birth includes a friend or relative being ill or dying between 18 weeks gestation and 8 weeks post birth.

Table 1 shows that $13 \%$ (19\%) of mothers experienced a friend or relative who died (was ill) during the first trimester and 14\% (15\%) experienced a friend or relative who died (was ill) in between mid-pregnancy and 8 weeks post birth. The incidence may appear high, most likely due to two factors. First, the question asks about any friend or relative. Hence, this may include anyone from a friendly neighbour to a great-aunt, meaning that many mothers may experience such an event. Second, the measure includes mothers who 
were only moderately or mildly affected. An alternative would be to create an IV based on the intensity by which the mother was affected, for example differentiating between being affected a lot or only mildly. However, the extent which mothers report being affected is potentially endogenous and as such we create just the binary indicators discussed above. Table 3 provides a breakdown across the various categories for the instruments. These are provided for the full data available in ALSPAC, though rates for mothers experiencing these events are the same as those reported in Table 1.

\section{Methodology}

We consider the following model for child outcomes

$$
y_{i}=\alpha+\beta M H_{i}+\delta X_{i}+u_{i}
$$

where $y_{i}$ denotes a set of outcomes for child $i$, including psychological, socio-emotional and cognitive outcomes. $M H_{i}$ denotes the mothers' mental health during early gestation (measured at 18 weeks gestation) or the perinatal period (measured at 8 weeks post birth). $X_{i}$ denotes a set of covariates, including child gender, ethnicity, dummies for month of birth, a quadratic in the mothers' age at birth, mother's education and social class, grandparents' education, and an indicator for whether the pregnancy was planned. $u_{i}$ denotes an idiosyncratic error term. We report heteroscedasticity robust standard errors throughout.

The mental health of mothers is likely to be endogenous. For example, environmental factors such as socio-economic position may drive the mental health of mothers and may

persist to drive the outcomes of children. Similarly, mental health is likely to be measured with error, leading to biased parameters. 
To deal with both sources of endogeneity, we adopt an instrumental variables strategy. For this, we follow the identification strategy used in Black et al. (2016) and Presson and Rossin-Slater (2018) and exploit the fact that ALSPAC mothers were asked to provide details on certain 'life events' that occurred at specific times during and shortly after pregnancy. We use the illness or death of a friend or relative before 18 weeks gestation as an instrument for early gestation maternal mental health, and we use the illness or death of a friend or relative between mid-pregnancy and 8 weeks post-birth as an instrument for perinatal maternal mental health. ${ }^{11}$

We show below that the instrumental variables satisfy the relevance assumptions necessary for IV. The IVs are strong predictors of mothers' mental health around pregnancy. Additionally the exclusion restriction assumes that the instrumental variables do not directly drive child outcomes except through the pathway of mothers' mental health. Using a similar identification strategy, Black et al (2016) point out several potential violations of treating the incidence of a relative dying during pregnancy as exogenous. They indicate that an early death of a grandparent may increase financial resources through inheritance, indicate poor health endowments, and/or may lead to a reduction in childcare. In our case, we combine instruments for a friend or relative dying, for which these arguments are valid, with the illness of a friend or relative, where all arguments are valid except the inheritance channel. We attempt to minimise the extent of these issues by conditioning on many measures of the mothers' socio-economic status including her social class and education, as well as the

\footnotetext{
${ }^{11}$ The death of a relative or spouse has also been used as an exogenous shock in other contexts. For example, Liberini et al. (2017) use the death of a spouse as a negative and exogenous shock to well-being to measure the effect of well-being on voting intentions (i.e. voting for the incumbent political party). Similarly, exploring the relationship between happiness and productivity, Oswald et al. (2015) show that individuals who report to have experienced recent tragedies (defined as bereavement or illness in the family) are disproportionately the ones who report lower happiness and who had lower productivity. They interpret these events as "unhappiness shocks".
} 
education of her parents. Additionally, in the robustness analysis, we stratify our regressions by whether the grandparents provided childcare when the child was between 15-38 months old. Our results that are not statistically different across groups, suggesting that a potential reduction in childcare is not driving our findings.

\section{Results}

\subsection{Main findings}

Our main results on the impact of mothers' mental health around pregnancy are provided in Tables 4-6. Each table is divided into two panels: Panel a) reports the effect of mothers' mental health reported at 18 weeks gestation; Panel b) reports the effect of mothers' mental health reported at 8 weeks post partum. For each mental health measure, we report OLS results in the first row and IV results in the second row. Finally each panel reports the F-statistics and coefficients relating to the two IVs from the first stage equations.

The first set of outcomes, presented in Table 4, include measures of child psychological scores. The first panel of OLS results reports that a standard deviation increase in (i.e. deterioration of) mothers' mental health in early gestation raises the depression score of their child by $8.5 \%, 23.0 \%$ and $23.8 \%$ of a standard deviation at ages 108 months (9 years), 115 months (9.6 years) and 140 months (or 11.6 years old) respectively.

When moving to the IV estimates, the effect of mothers' mental health problems at 18 weeks gestation persist for child depression scores at ages 108 and 115 months. ${ }^{12}$ As expected,

\footnotetext{
${ }^{12}$ The first stage F-statistics range between 12-13 depending on the sample size, suggesting we do not have problems with weak instruments. However, the first stage coefficients show that this is driven by friends/family being ill, rather than having died. This is different when specifying mental health at 8 weeks post-birth, where both instruments predict variation in mental health. We come back to this below.
} 
the IV estimates exhibit less precision than OLS results. However, the magnitudes are larger and they remain statistically significant, where a standard deviation increase in mothers' mental health problems raises child depression by $52.7 \%$ and $53.6 \%$ of a standard deviation. However, by the age of 140 months, the coefficient has fallen to $29.8 \%$ of a standard deviation and is no longer statistically significant.

Note that for all columns, the IV estimate is larger than the OLS estimate which may suggest one of two things. Firstly, it could be indicative of measurement error in our measure of mothers' mental health. Secondly, it may indicate that we are estimate a local average treatment effect (LATE). Mothers more likely to respond to the instrumental variables may be those with inherent mental health issues. Whilst we do control for the mothers' baseline mental health, we explore the possibility that our estimates are a LATE by analysing heterogeneity in the effects by mothers' pre-pregnancy experience of depression. Only $7.5 \%$ of mothers report having experienced depression in the past (see Table 2). When we exclude these mothers from our analysis the results remain substantively similar ruling out an effect local to mothers with an underlying propensity for poor mental health. ${ }^{13}$ Our results are not driven by mothers with a history of mental health issues which therefore suggests that measurement error may be causing the higher estimates in IV compared to OLS.

Panel b) of Table 4 reports the effect of maternal mental health recorded at 8 weeks post birth on child depression scores. The results are broadly similar to those reported above with one exception. Whilst the effect of mental health during early pregnancy on child depression had faded out by age 140 months (driven by a lower magnitude rather than a larger standard error), there is still an effect of mothers' mental health measured at 8 weeks post partum on child depression at 140 months. The coefficient is slightly smaller than the estimate at 108

\footnotetext{
${ }^{13}$ Results available upon request.
} 
and 115 months, but remains statistically significant at the $10 \%$ level.

Deming (2017) argues that socio-emotional skills are increasingly predictive for longer run labour market achievement. We explore the effect of mothers' mental health around pregnancy on a range of socio-emotional skills of children, measured through the Strengths and Difficulty Questionnaires measured between 81-198 months. The results in Table 5 again suggest very strong and consistent effects of mothers' mental health around pregnancy on SDQ scores in the OLS regressions. This is true of mothers' mental health measured at 18 weeks gestation (Panel a) as well as 8 weeks post birth (Panel b).

For the IV analyses, the effect of mothers' mental health in early pregnancy show a clear fade-out across child age. At 81 months a 1 standard deviation increase in mothers' mental health issues raises child SDQ problems by $56.6 \%$ of a standard deviation. The corresponding coefficient is not statistically significant from 115 months onwards and the magnitude falls close to zero as the child ages. At 8 weeks post birth, increases in mothers' poor mental health raises reported SDQ problems for the child measured up to 140 months. At 157 months and 198 months, the coefficient remains positive but is not statistically different to zero. Again, the evidence suggests that any effect of mothers' mental health either during pregnancy or soon after drives child outcomes measured relatively early in the lifecycle. However, these results fade-out by mid-adolescence (age of 16).

Finally, we consider cognitive outcomes of the children in Table 6. OLS estimates suggest that mothers' poor mental health, both in early gestation and soon after birth, is associated with lower cognitive achievement across all compulsory schooling ages, with a 1 standard deviation deterioration in mental health reducing children's test scores by 0.03-0.07 standard deviations. However, once we instrument for maternal mental health, the estimates are no longer statistically significant. The general finding of no significant effect on cognitive 
outcomes is in line with Black et al (2016) who find no effect of bereavement during pregnancy on later cognitive outcomes of children.

The fact that children's cognitive scores do not respond to sudden changes in maternal mental health due to bereavement or illness of family/friends also suggests that our instruments are not solely picking up some measure of the socio-economic environment. Indeed, if they did, given that all child outcomes used here have been shown to be positively correlated with socio-economic position of the household, we would expect the IV estimates to show a similar negative effect of maternal mental health on all child outcomes - psychological, socio-emotional, as well as cognition - and across measures recorded at different child ages. We do not find this, suggesting that the IV estimates perform well in picking up the effect of a deterioration in maternal mental health driven by bereavement or illness among mothers' relatives/friends.

One advantage of our methodology and dataset compared to the existing literature, is the ability to measure mothers' mental health during pregnancy and very soon after birth. Rather than relying on an ITT reduced form estimation of a stressful event on child outcomes, we construct a set of instrumental variables for a stressful events from which we can identify the ATE of mothers' mental health. Tables 4 - 6 report the F-statistics relating to the two instrumental variables together with their estimated coefficients from the first stage regressions. The first stage $\mathrm{F}$ statistic for the IV regressions varies across specifications, mainly due to small differences in the sample size (the covariates and instruments employed in the first-stage regression are constant across models within each panel, but this is not the case for models of outcomes). The statistics show that the instruments are sufficiently strong at predicting mothers' mental health. The coefficients on the instrumental variables show that the incidence of a friend or relative either dying or being ill raises mental health 
problems of the mother. When considering the regressions of mothers' mental health at 18 weeks gestation, the coefficient on the second IV, the death of a friend or relative, is often not significant suggesting that the variation is coming predominantly from the illness of a friend or relative. ${ }^{14}$ However, for the regressions of mothers' mental health at 8 weeks post birth, the incidence of both IVs statistically significantly worsen mothers' mental health. Finally, the p-values of the Hansen test for over-identification are greater than 0.05 in all specifications except one, suggesting little concern of the exclusion restriction being violated.

\subsection{Fade-out versus Attrition}

Child depression and socio-emotional skills are measured through a survey. As the child ages, sample sizes fall due to attrition in this survey. Table 5 shows that this attrition is particularly prevalent for the socio-emotional skills measured at 198 months, where the sample size is around 3,300 compared to around 6,200-6,400 at 81 months. It might therefore be that, rather than the effect of maternal mental health fading out over time, the reduction in the estimates may be driven by non-random sample attrition. To test whether this is the case, Table A.2 estimates the IV regressions of mothers' mental health at 18 weeks gestation and 8 weeks post-birth, selecting on the sample of mother-child pairs with non-missing SDQ scores at 198 months. ${ }^{15}$

Selecting on the smaller sample, the conclusions of our benchmark specification remain unchanged. The effect of mothers' mental health at 18 weeks gestation on child depression at 140 months is not statistically significant, whereas mental health measured at 8 weeks after birth has an effect on depression at 140 months which is significant at the $10 \%$ level. For

\footnotetext{
${ }^{14}$ Appendix Table A.1 reports results when just one IV is used - the illness of a friend or relative. The results and our conclusions are qualitatively very similar.

${ }^{15}$ The sample sizes vary slightly across outcomes in Table A.2 due to item-missing observations.
} 
the SDQ outcomes, we find a similar pattern as that above: statistically significant effects of maternal mental health for the earlier SDQ measures, which reduce as the child ages and is no longer significant from 157 months onwards.

\subsection{Heterogeneity by Gender}

There is evidence from studies of fetal brain development that elevated maternal cortisol concentrations are associated with enlarged right amygdala volume in girls (Buss et al., 2012). ${ }^{16}$ This suggests child gender differences in the impact of maternal mental health and stress. We test this assumption by repeating the analysis on outcomes by child gender. The results are reported in Tables A.3-A.4.

Splitting the sample reduces the precision of the estimates. However what can be seen is that the coefficients of mothers' mental health on the depression scores are larger for boys compared to girls (the exception is in the regression of mothers' mental health at 8 weeks post birth on depression at 115 months). On the other hand, coefficients on child socioemotional skills tend to be larger for girls compared to boys (again there are exceptions for measures at 157 and 198 months). Due to lack of precision, however, the gender differences are not statistically significant.

Consistent with the results for the full sample, we find no evidence that maternal mental health impacts on cognitive ability for boys or girls (Table A.4).

\footnotetext{
${ }^{16}$ In a related literature it is noted that Powdthavee and Vignoles (2008) in studying the intergenerational transmission of well-being find a link between maternal distress their children's life satisfaction, but that this holds only for daughters, not sons.
} 


\section{Robustness analysis}

\subsection{Validity of instrumental variables}

Our set of instrumental variables includes indicators for the mother experiencing the illness of a friend or relative and an indicator for experiencing the death of a friend or relative. In this section we explore the validity of the instrumental variables.

First, we interpret our instrumental variables strategy as isolating a shock to mothers' mental health in a particular stage of pregnancy: either between the start of pregnancy and 18 weeks gestation, or between 18 weeks gestation and 8 weeks post birth. It is possible that mothers who are predisposed to mental health problems are more easily triggered into a state of depression by these events. We account for this by including a dummy indicating whether the mother ever suffered from depression, proxying for a baseline measure of mental health.

Secondly, the instruments may be assigned non-randomly across the population. Whilst we do control for measures of family socio-economic status, it is impossible to control for all potential confounders and there remains a possibility that the instrumental variables are picking up unobserved traits that also drive child outcomes. For example, it may be that mothers of lower socio-economic status are more likely to have friends or relatives becoming ill or dying, and this is driving the results. We address this by estimating the effect of mental health at 8 weeks post birth on child outcomes, conditioning on whether the mother experienced the illness or death of a friend or family member between the start of pregnancy

and 18 weeks gestation (i.e. the instruments for mental health at 18 weeks gestation). This means that the instrumental variable for perinatal mental health should pick up changes in the incidence of illness/death of a friend/family from mid-pregnancy, independent of 
the incidence in the first 18 weeks of pregnancy. This will remove the possibility that the instrumental variables at 8 weeks post birth are driven by a general tendency for friends or relatives being ill or dying. Table A.5 shows that the results are robust to the inclusion of the measures of death or illness of a friend or family measured in early pregnancy.

A third threat to the validity of our instrumental variables strategy would occur if the instruments directly affected children. One channel in particular would be if the relative of the mother who was ill or died during pregnancy was a grandparent, who subsequently spent less or no time interacting with the child. ${ }^{17}$ ALSPAC contains information on the childcare provided by grandparents. Tables A.6 and A.7 split the sample by whether a grandparent carried out childcare when the child was aged 15, 24 and 38 months old. The tables report the estimated coefficients where we focus on the outcomes for which we found significant effects of mothers' mental health. We report a t-statistic for the test of equality of coefficients for the sample where the grandparent does and does not provide childcare and in all cases we cannot reject the null that the coefficients are equal. ${ }^{18}$ This therefore strengthens our belief that the instrumental variables do not pick up a direct effect through changes in time investments made by grandparents.

\section{Fade-out: potential mechanisms}

The literature examining the effect of an episode of stress during pregnancy - measured through death of a parent, an earthquake or other event - tends to find that stress leads to worse child outcomes at birth. However, it is rare to find negative long-run effects from

\footnotetext{
${ }^{17}$ The same could be true of the illness or death of a friend, which may again reduce time spent with the child by the friend.

${ }^{18}$ Splitting the sample by whether a friend provides childcare at 15, 24 and 38 months also shows no statistically significant differences in the estimates (results available upon request).
} 
stress during pregnancy. For example, Black et al., (2016) find no long-run effect on child cognitive skills; Li et al., (2010) find small differences in obesity at ages 10-12 depending on whether the child's mother was bereaved during pregnancy, although the differences were not statistically significant. ${ }^{19}$

Our analysis finds statistically significant effects of mothers' mental health on child outcomes up to 140 months (11.7 years) but these effects do not persist into adolescence. Hence, it suggests that any effect of poor mental health around pregnancy fades out in the long-run.

To indirectly explore potential mechanisms for this fade-out, we examine how the incidence of mothers mental health problems around pregnancy affects maternal investments during the early childhood years. Table A.8 provides descriptives for a set of measures of parental investments observed when the child was aged 6 to 42 months. They include indicators for maternal breastfeeding; scores reflecting the quality of mothers' parenting, measured between 6-42 months; scores reflecting the extent to which mothers engaged in teaching their child certain skills, measured between 18-42 months; scores reflecting the activities mothers engage in with their children, measured between 6-42 months; and finally two toy scores which measure the quality of the home learning environment. Table A.9 lists the set of variables ALSPAC used to create the parenting, teaching, activity, and toy score scores.

Table 7 presents regression coefficients on mothers' mental health at 18 weeks gestation (column 1) or 8 weeks post birth (column 2) from separate regressions, where the dependent variable is given by the different parental investment measures listed in the rows. The estimates are derived from IV regressions using the set of controls in our benchmark specification. It is apparent from Table 7 that, where the coefficients are statistically significant, they are positive (there is one exception; the parenting score at 18 months). In general

\footnotetext{
${ }^{19}$ In some specifications, there was a significant effect on BMI at ages 10-12 but not before 10 or after 12.
} 
therefore, an increase in mental health problems of mothers around pregnancy leads to an increase in her investments. This suggests that mothers to some extent compensate for the spell of mental health problems by raising investments in their children post birth. Specifically, an increase in mental health problems at 18 weeks gestation raises the parenting score at 6 months by 0.566 and the toy score at 24 months by 2.209 . An increase in the mental health issues postpartum raises the incidence of breastfeeding by 0.588 (the mean level of breastfeeding in the full sample is 0.627 ); raises breastfeeding for at least three months by 0.162 and raises the teaching score at 18 months by 0.628 . Hence, this may suggest that the change in maternal investments in response to poor mental health partially explains why we find no long-run effect of mothers' mental health issues on child depression and socioemotional outcomes. Note ofcourse that our interpretation is speculative, as we cannot say this with complete certainty.

\section{Conclusion}

It is well established that adverse early life events can have serious long-term consequences, affecting child development. Such negative events or shocks may occur in utero impacting on fetal development (for example, Currie, 2011; Almond and Currie, 2011a, 2011b). To date, much of the literature that focuses on shocks during pregnancy considers shocks to the physical health of mothers and the resulting impact on their children. The impact of experiences of poor mental health during pregnancy has received less attention, despite this being a crucial time due to the rapid development of children in utero. In particular, poor maternal mental health and stress during pregnancy has been associated with

increased levels of cortisol and linked to a number of effects on a child's development ranging 
from lower fetal growth and birth weight to an increased risk of affective disorders and lower cognitive skills. Poor mental health during pregnancy and soon thereafter may also have important behavioural consequences in terms of a mother's investments in children.

Due to a general paucity of data that directly measure maternal mental health during pregnancy, studies that have considered its impact on a child's later life outcomes have tended to rely on proxy measures such as a death of a family member (e.g. Black, Devereux and Salvanes, 2016) or natural disasters (e.g. Currie and Rossin-Slater, 2015) and an intentionto-treat identification strategy. The extent to which such shocks actually affect a mother's mental health, however, is often unknown. This paper contributes to the literature on early life development on later life outcomes by examining maternal mental health during both early gestation and shortly following birth on key psychological, socio-emotional and cognitive skills of a child and into adolescence.

Our results show that poor maternal mental health in the period of early gestation (18 weeks gestation) or shortly following birth significantly raises the risk of child depression and negatively impacts socio-emotional skills. These are shown for both OLS estimates and our favoured IV results. However, as the child ages, we observe a fade-out in the IV estimates of mothers' mental health. Similar to the existing literature, we do not find an impact on children's cognitive abilities.

We provide evidence suggesting that mothers' mental health around pregnancy drives the investments made by mothers in the early years of her child's life. Specifically, her breastfeeding behaviour, ability to interact with her child and the home learning environment is improved by the incidence of mental health problems. This suggests that a reason for the lack of long-run effect of mothers' mental health stems from maternal compensatory behaviours in the months after birth. 
Given the high incidence of clinical depressive symptoms during pregnancy and postpartum depression, a greater understanding of the long term consequences on a child's development and outcomes is warranted to inform public policy. This may be particularly so around the management and care of maternal depression and stress, but also in enabling appropriate behaviours and investments in infants and young children where maternal mental health problems are present. For example, this might consist of additional specialist care and support for women at home or in maternity units through advice on medication and lifestyles and providing counselling and cognitive behavioural therapy where appropriate. Such policies, while targeted at supporting mothers during pregnancy and in the perinatal period, may also have important benefits to their child's socio-emotional and psychological development. 


\section{References}

[1] Almond, D., Mazumder, B. The 1918 influenza pandemic and subsequent health outcomes: An analysis of SIPP data. American Economic Review. 2005; 95 (2): 258-62.

[2] Almond, D. Is the 1918 Influenza pandemic over? Long-term effects of in utero influenza exposure in the post-1940 US population. Journal of Political Economy, 2006; 114(4): 672712 .

[3] Almond, D., Edlund, L., Palme, M. Chernobyl's subclinical legacy: Prenatal exposure to radioactive fallout and school outcomes in Sweden. Quarterly Journal of Economics, 2009; 124 (4): $1729-72$.

[4] Almond, D., Edlund, L., Li, H., Zhang, J. Long-term effects of the 1959-61 China famine: Mainland China and Hong Kong. In The Economic Consequences of Demographic Change ion East Asia. NBER-EASE Vol 19. Eds. T. Ito and A. K. Rose, 321-50. Chicago: University of Chicago Press, 2010.

[5] Almond, D., Currie, J., Human capital development before age five. In Handbook of Labour Economics, Vol 4, Part B, edited by Orley Ashenfelter and David Card. 2011a, 1315-1486. Amsterdam: Elsevier.

[6] Almond, D., Currie, J., Killing me softly: The fetal origins hypothesis. Journal of Economic Perspectives, 2011b; 25(3): 153-172.

[7] Angold, A., Costello, E.J., Messer, S.C., Pickles, A., Winder, F., et al., 1995. The development of a short questionnaire for use in epidemiological studies of depression in children and adolescents. International Journal of Methods in Psychiatric Research 5 (4), 237-249.

[8] Bharadwaj, P., Loken, K. V., Neilson, C. Early life health interventions and academic achievement. American Economic Review, 2013; 103 (5): 1862-1891. 
[9] Black, Sandra. E, Devereux, Paul J. and Salvanes, Kjell, G. (2016). "Does grief transfer across generations? Bereavements during pregnancy and child outcomes", American Economic Journal: Applied Economics, 8(1): 193-223.

[10] Black, S. E., Butikofer, A., Devereux, P.J., Salvanes, K. G. This is only a test? The long-run impacts of prenatal exposure to radioactive downfall. National Bureau of Economic Research (NBER) Working Paper 18987; 2013.

[11] Boyd, A., Golding, J., Macleod, J., Lawlor, D., Fraser, A., Henderson, J., Molloy, L., Ness, A., Ring, S. and Davey Smith, G. (2013). 'Cohort profile: the 'Children of the 90s' - the index offspring of the Avon Longitudinal Study of Parents and Children', International Journal of Epidemiology, 42(1), 111-27.

[12] Brown, Ryan. (2014). "The intergenerational impact of terror: does the 9/11 tragedy reverberate into the outcomes of the next generation?", HiCN working paper 165 .

[13] Bruckner, T.A., Modin, B., Vagero, D. (2014). Cold ambient air temperature in utero and birth outcomes in Uppsala, Sweden, 1915-1929. Annals of Epidemiology, 2014; 24(2): 116-21.

[14] Buss C., Davis, E.P., Shahbaba, B., Pruessner, J.C., Head, K., Sandman, C.A. (2012). "Maternal cortisol over the course of pregnancy and subsequent child amygdala and hippocampus volumes and affective problems", PNAS, Published online April 23, 2012.

[15] Currie, J. Inequality at Birth: Some causes and consequences. American Economic Review, 2011; 101(3): 1-22.

[16] Currie, Janet and Rossin-Slater, Maya. (2013). "Weathering the storm: hurricanes and birth outcomes", Journal of Health Economics, 31: 487-503.

[17] Currie, J., Stabile, M., Manivong, P., Roos, L. L. Child Health and Young Adult Outcomes. The Journal of Human Resources, 2010; 45(3): 517-546. 
[18] Davis, E.P. et al. (2007). "Prenatal exposure to maternal depression and cortisol influences infant temperament", Journal of Am Acad Child Adolesc Psychiatry, 46: 737-746.

[19] Davis, E.P. Glynn, L.M., Waffarn, F., Sandman, C.A. (2011). "Prenatal maternal stress programs infant stress regulation", Journal of Child Child Psychol Psychiatry, 52: 119-129.

[20] Del Bono, E., Rabe, B. Breastfeeding and child cognitive outcomes: Evidence from a hospitalbased breastfeeding support policy. Institute for Social and Economic Research, 2012; Research Paper No 2012-29: December 2012.

[21] Deming, David. J. (2017). The growing importance of social skills in the labor market, Quarterly Journal of Economics, 1593-1640.

[22] Fraser, A., Macdonald-Wallis, C., Tilling, K., Boyd, A., Golding, J., Davey Smith, G., Henderson, J., Macleod, J., Molloy, L., Ness, A., Ring, S., Nelson, S. and Lawlor, D. (2013). 'Cohort profile: the avon longitudinal study of parents and children: ALSPAC mothers cohort', International Journal of Epidemiology, 42(1), 97-110.

[23] Gitau, R., Cameron, A., Fisk, N. M. and Glover, V. (1998). "Fetal exposure to maternal cortisol", The Lancet, 352: 707-708.

[24] Goodman, R., 1997. The strengths and difficulties questionnaire: a research note. Journal of Child Psychology and Psychiatry and Allied Disciplines 38 (5), 581-586.

[25] von Hinke, S., Jones, A. Cohort Data in Health Economics. In (Ed.), The Oxford Handbook of Panel Data, 2015. Oxford University Press.

[26] Kelly, E. The scourge of Asian Flu: In utero exposure to pandemic influenza and the development of a cohort of British children. Journal of Human Resources, 2011; 46(4): 669-94.

[27] Le, H, T., Nguyen, H. T. (2018). "The impact of maternal mental health shocks on child health", American Journal of Health Economics, 4(2): 185-225. 
[28] Li, J., Wang, Z-N., Chen, Y-P., Dong, Y-P., Shauai, H-L., Xiao, X-M., Reichatzeder, C., Hecher, B. (2011). "Late gestational maternal serum cortisol in inversely associated with fetal brain growth", Neurosci Biobehav Rev, 36: 1085-1092.

[29] LeWinn K.Z., Stroud, L.R., Molnar, B.E., Ware, J.H., Koenen, K.C., and Buka, S.L. (2009). "Elevated maternal cortisol levels during pregnancy are associated with reduced childhood IQ", International Journal of Epidemiology, 38: 1700-1710.

[30] Liberini, F., and Redouano, M., and Proto, E. (2017). "Happy voters", Journal of Public Economics, 146: 41-57.

[31] Lupien, S.J., Parent, S., Evans, A.C., Tremblay, R.E., Zelazo, P.D., Corbo, V., Pruessner, J.C., Seguin, J.R. (2011). "Larger amygdala but no change in hippocampal volumn in 10-yearold children exposed to maternal depressive symptomatology since birth", Proc Natl Acas Sci USA, 108: 14324-14329.

[32] Mansour, Hani. and Rees, Daniel. R. (2012). "Armed conflict and birth weight: evidence from the al-Aqsa intifada", Journal of Development Economics, 99: 190-199.

[33] Marcus, S. M., Flynn, H. A., Blow, F. C. and Barry, K. L. (2003). "Depressive symptoms among pregnant women screened in obstetrics settings", Journal of Women's Health, 12: 373380.

[34] Miller, L. J. (1992). "Comprehensive care of pregnant mentally ill women", Journal of Mental Health Administration, 19: 170-177.

[35] Oswald, A. and Proto, E. and Sgroi, D. (2015). "Happiness and productivity", Journal of Labor Economics, 33(4): 789-822. 
[36] Powdthavee, Nattavudh and Vignoles, Anna. (2007). "Mental Health of Parents and Life Satisfaction of Children: A Within-Family Analysis of Intergenerational Transmission of WellBeing", Social Indicators Research, 88: 397-422.

[37] Olafsson, Arna. (2016). "Household Financial Distress and Initial Endowments: Evidence from the 2008 Financial Crisis", Health Economics, 25, 43-56.

[38] Presson, Petra and Rossin-Slater, Maya. (2018). "Family ruptures, stress, and the mental health of the next generation", American Economic Review, 108(4-5), 1214-1252.

[39] Scholte, R. S., van den Berg, G. J., Lindeboom, M. The long-run effects of gestation during the Dutch hunger winter famine on labour market and hospitalization outcomes. Institute for the Study of Labor (IZA) Discussion Paper 6307, 2012.

[40] Simeonova, Emilia. (2009). "Out of sight, out of mind? The impact of natural disasters on pregnancy outcomes", CESIFO working paper 2814.

[41] Sohr-Preston, Sara. L. and Scaramella, Laura. V. (2006). "Implications of timing of maternal depressive symptoms for early cognitive and language development", Clinical Child and Family Psychology Review, 9(1): 65-83.

[42] Torche, Florencia. (2011). "The effect of maternal stress on birth outcomes: exploiting a natural experiment", Demography, 48(4): 1473-1491.

[43] Tottenham, N., Hare, T.A., Quinn, B.T., McCarry, T.W., Nurse, M., Gilhooly, T., Milner, A., Galvan, A., Davidson, M.C., Eigsti, I-M., Thomas, K.M., Freed, P., Booma, E.S., Gunnar, M., Altemus, M., Aronson, J., Casey, B.J. (2010). "Prolonged institutional rearing is associated with atypically large amygdala volume and difficulties in emotion regulation", Dev Sci, 13: 46-61. 
[44] Walker, L.O., Cooney, A. T. and Riggs, M. W. (1999). "Psychosocial and demographic factors related to health bejaviors in the 1st trimester", Journal of Obstetric, Gynecological and Neonatal Nursing, 28: 606-614.

[45] Zuckerman, G., Amaro, H., Bauchner, H. and Cabral, H. (1989). "Depressive symptoms during pregnancy: relationship to poor health behaviors", American Journal of Obstetrics and Gynecology, 160: 1107-1111. 


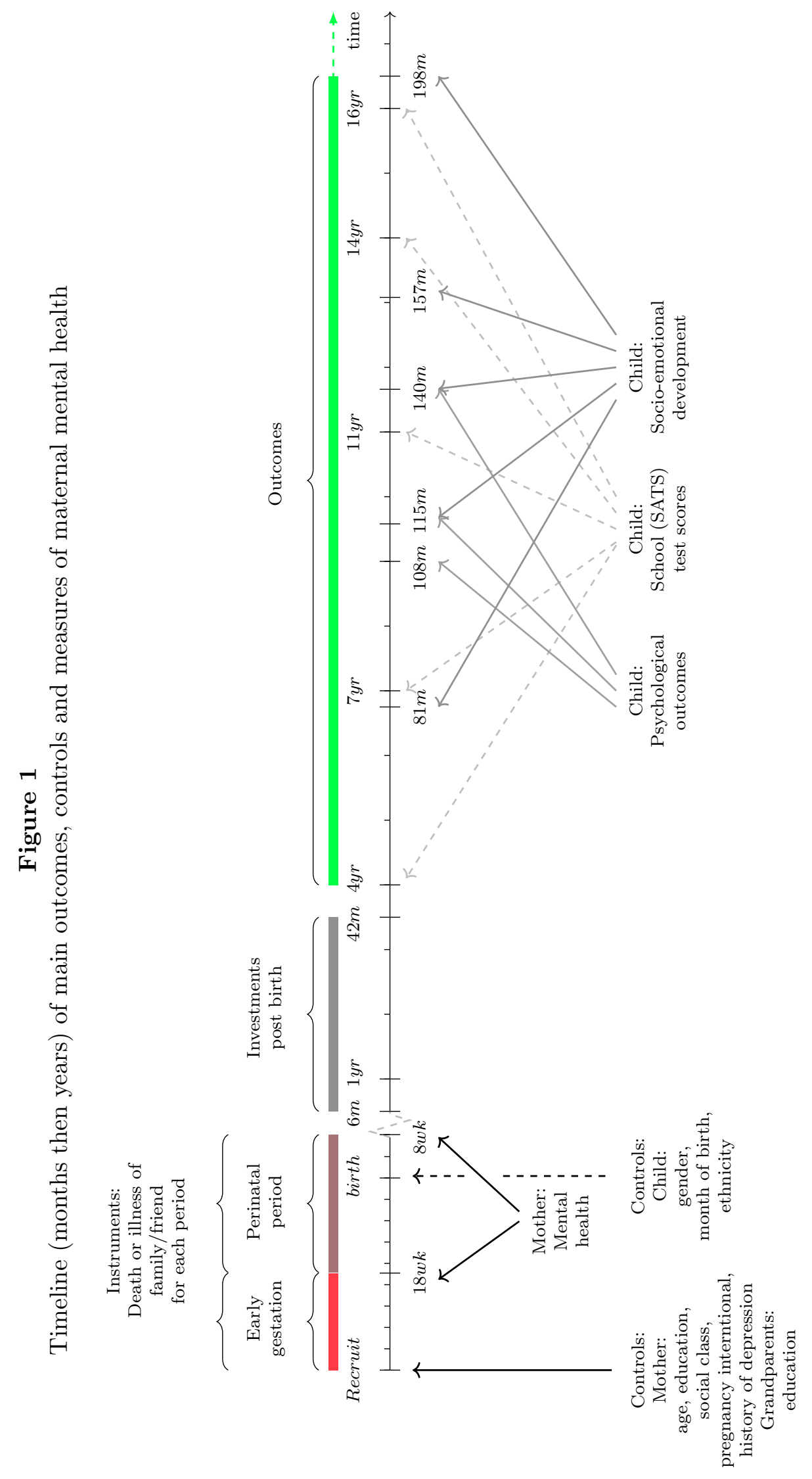


Table 1

Descriptive statistics for mothers' mental health, child outcomes, instrumental variables

\begin{tabular}{lccc}
\hline & $\mathrm{N}$ & Mean & $\begin{array}{c}\text { Standard } \\
\text { Deviation }\end{array}$ \\
\hline Mothers' mental health & & & \\
Mothers mental health (CCEI) 18 weeks gestation & 8,132 & -0.077 & 0.958 \\
Mothers mental health (CCEI) 8 weeks post birth & 8,132 & -0.057 & 0.943 \\
\hline Child outcomes & & & \\
Depression 108 months & 5,301 & -0.015 & 0.993 \\
Depression 115 months & 5,884 & -0.010 & 0.977 \\
Depression 140 months & 5,395 & -0.016 & 0.983 \\
Strengths difficulties 81 months & 6,397 & -0.028 & 0.987 \\
Strengths difficulties 115 months & 5,864 & -0.034 & 0.978 \\
Strengths difficulties 140 months & 5,420 & -0.030 & 0.978 \\
Strengths difficulties 157 months & 4,491 & -0.021 & 0.993 \\
Strengths difficulties 198 months & 3,330 & -0.020 & 0.980 \\
Entry school assessment & 5,851 & 0.119 & 0.964 \\
Key stage 1 (age 7) & 7,647 & 0.137 & 0.946 \\
Key stage 2 (age 11) & 7,289 & 0.140 & 0.919 \\
Key stage 3 (age 13) & 6,685 & 0.156 & 0.941 \\
Key stage 4 (age 15/16) & 7,387 & 0.153 & 0.933 \\
Instrumental Variables & & & \\
Friend/relative died trimester 1 & 8,549 & 0.133 & 0.339 \\
Friend/relative ill trimester 1 & 8,549 & 0.195 & 0.397 \\
Friend/relative died trimester 2 & 8,155 & 0.135 & 0.342 \\
Friend/relative ill trimester 2 & 8,153 & 0.149 & 0.356 \\
\hline
\end{tabular}


Table 2

Descriptive statistics for covariates

\begin{tabular}{lccc}
\hline & $\mathrm{N}$ & Mean & $\begin{array}{c}\text { Standard } \\
\text { Deviation }\end{array}$ \\
& & & \\
& & & \\
Mother level variables & 8,132 & 0.075 & 0.264 \\
Mother ever had depression & 8,132 & 28.771 & 4.549 \\
Mother age & 8,132 & 0.132 & 0.338 \\
Mum education: CSE/none & 8,132 & 0.460 & 0.498 \\
Mum education: Vocational/O level & 8,132 & 0.259 & 0.438 \\
Mum education: A level & 8,132 & 0.149 & 0.356 \\
Mum education: Degree & 8,132 & 0.060 & 0.238 \\
Mum class: I - Professional & 8,132 & 0.321 & 0.467 \\
Mum class: II - Managerial & 8,132 & 0.435 & 0.496 \\
Mum class: IIInm - Skilled non-manual & 8,132 & 0.072 & 0.259 \\
Mum class: IIIm - Skilled manual & 8,132 & 0.111 & 0.314 \\
Mum class: IV - Semi-skilled / unskilled & 8,132 & 0.752 & 0.432 \\
Pregnancy intentional & & & \\
Grandparent level variables & 8,132 & 0.322 & 0.467 \\
Maternal grandmother education: CSE/none & 8,132 & 0.259 & 0.438 \\
Maternal grandmother education: Vocational/O level & 8,132 & 0.162 & 0.368 \\
Maternal grandmother education: A level/Degree & 8,132 & 0.257 & 0.437 \\
Maternal grandmother education: Missing & 8,132 & 0.262 & 0.440 \\
Maternal grandfather education: CSE/none & 8,132 & 0.248 & 0.432 \\
Maternal grandfather education: Vocational/O level & 8,132 & 0.195 & 0.396 \\
Maternal grandfather education: A level/Degree & 8,132 & 0.295 & 0.456 \\
Maternal grandfather education: Missing & & & \\
Child level variables & 8,132 & 0.483 & 0.500 \\
Child female dummy variable & 8,132 & 0.039 & 0.194 \\
Month of birth & & 5.619 & 3.692 \\
Child is non-white & & & \\
\hline
\end{tabular}

CSE and 'O'levels refer to examinations taken at age 16, and 'A'levels at age 18. 


\section{Table 3}

Breakdown of instrumental variables

\begin{tabular}{lcccc}
\hline \multicolumn{4}{c}{ Period: Start of pregnancy to 18 weeks gestation } \\
& $\begin{array}{c}\text { Friend or relative died } \\
\text { since pregnancy }\end{array}$ & $\begin{array}{c}\text { Friend or relative was ill } \\
\text { since pregnancy }\end{array}$ \\
& $\mathrm{N}$ & $\%$ & $\mathrm{~N}$ & $\%$ \\
\hline Didn't happen & 10,405 & 87.11 & 9,660 & 80.92 \\
No effect at all & 283 & 2.37 & 646 & 5.41 \\
Mildly affected & 545 & 4.56 & 829 & 6.94 \\
Moderately/fairly affected & 355 & 2.97 & 442 & 3.70 \\
Affected a lot & 357 & 2.99 & 361 & 3.02 \\
\hline
\end{tabular}

Period: Between mid pregnancy and 8 weeks post birth

Friend or relative died Friend or relative was ill

\begin{tabular}{lcccc} 
& \multicolumn{2}{c}{ since pregnancy } & \multicolumn{2}{c}{ since pregnancy } \\
& $\mathrm{N}$ & $\%$ & $\mathrm{~N}$ & $\%$ \\
\hline Didn't happen & 10,058 & 86.48 & 9,945 & 85.57 \\
No effect at all & 292 & 2.51 & 426 & 3.67 \\
Mildly affected & 511 & 4.39 & 547 & 4.71 \\
Moderately/fairly affected & 378 & 3.25 & 363 & 3.12 \\
Affected a lot & 391 & 3.36 & 341 & 2.93 \\
\hline
\end{tabular}


Table 4

Effect of mothers' mental health on child depression

\begin{tabular}{|c|c|c|c|}
\hline Child age & $\begin{array}{c}(1) \\
108 \text { months }\end{array}$ & 115 months & 140 months \\
\hline \multicolumn{4}{|c|}{ Panel a) Mental health at 18 weeks gestation } \\
\hline OLS & $\begin{array}{c}0.085^{* * *} \\
(0.015)\end{array}$ & $\begin{array}{c}0.230 * * * \\
(0.015)\end{array}$ & $\begin{array}{c}0.238^{* * *} \\
(0.016)\end{array}$ \\
\hline IV & $\begin{array}{c}0.527^{* *} \\
(0.234)\end{array}$ & $\begin{array}{c}0.536^{* *} \\
(0.230)\end{array}$ & $\begin{array}{c}0.298 \\
(0.201)\end{array}$ \\
\hline Observations & 5,301 & 5,884 & 5,395 \\
\hline F statistic 1st Stage & 13.20 & 11.57 & 12.74 \\
\hline Hansen Test p-value & 0.782 & 0.0998 & 0.510 \\
\hline \multicolumn{4}{|l|}{ First stage coefficients } \\
\hline Friend/relative ill & $\begin{array}{c}0.153^{* * *} \\
(0.033)\end{array}$ & $\begin{array}{c}0.132^{* * *} \\
(0.031)\end{array}$ & $\begin{array}{c}0.129^{* * *} \\
(0.031)\end{array}$ \\
\hline Friend/relative died & $\begin{array}{c}0.046 \\
(0.036)\end{array}$ & $\begin{array}{c}0.050 \\
(0.034)\end{array}$ & $\begin{array}{l}0.065^{*} \\
(0.035)\end{array}$ \\
\hline \multicolumn{4}{|c|}{ Panel b) Mental health at 8 weeks post birth } \\
\hline OLS & $\begin{array}{c}0.106^{* * *} \\
(0.017)\end{array}$ & $\begin{array}{c}0.263^{* * *} \\
(0.017)\end{array}$ & $\begin{array}{c}0.266^{* * *} \\
(0.019)\end{array}$ \\
\hline IV & $\begin{array}{c}0.474^{* *} \\
(0.225)\end{array}$ & $\begin{array}{c}0.469 * * \\
(0.208)\end{array}$ & $\begin{array}{l}0.401^{*} \\
(0.215)\end{array}$ \\
\hline Observations & 5,136 & 5,714 & 5,249 \\
\hline F statistic 1st Stage & 13.54 & 12.43 & 11.92 \\
\hline Hansen Test p-value & 0.948 & 0.00166 & 0.374 \\
\hline \multicolumn{4}{|l|}{ First stage coefficients } \\
\hline Friend/relative ill & $\begin{array}{c}0.107^{* * *} \\
(0.035)\end{array}$ & $\begin{array}{c}0.095^{* * *} \\
(0.033)\end{array}$ & $\begin{array}{c}0.103^{* * *} \\
(0.035)\end{array}$ \\
\hline Friend/relative died & $\begin{array}{c}0.139^{* * * *} \\
(0.039)\end{array}$ & $\begin{array}{c}0.130^{* * * *} \\
(0.037)\end{array}$ & $\begin{array}{c}0.127^{* * * *} \\
(0.038)\end{array}$ \\
\hline
\end{tabular}

Panel a) shows the effect of mothers' mental health at 18 weeks gestation; Panel b) shows the effect of mothers' mental health at 8 weeks post birth. All regressions control for child gender, ethnicity, dummies for month of birth, mothers' age at birth, mothers' education and social class, grandparents' education, whether mother had experienced depression in the past, and whether the pregnancy was planned. Instrumental variables: Panel a) - death of a friend or relative, and illness of a friend or relative between the start of pregnancy and 18 weeks gestation; Panel b) - death of a friend or relative and illness of a friend or relative between 18 weeks gestation and 8 weeks post birth. 
Table 5

Effect of mothers' mental health on child socio-emotional outcomes (SDQ)

\begin{tabular}{|c|c|c|c|c|c|}
\hline Child age & $\begin{array}{c}(1) \\
81 \text { months }\end{array}$ & $\begin{array}{c}(2) \\
115 \text { months }\end{array}$ & 140 months & $\begin{array}{l}(4) \\
157 \text { months }\end{array}$ & $\begin{array}{c}(5) \\
198 \text { months }\end{array}$ \\
\hline \multicolumn{6}{|c|}{ Panel a) Mental health at 18 weeks gestation } \\
\hline \multirow[t]{2}{*}{ OLS } & $0.245^{* * *}$ & $0.239^{* * *}$ & $0.229^{* * *}$ & $0.211^{* * *}$ & $0.196^{* * *}$ \\
\hline & $(0.014)$ & $(0.015)$ & $(0.015)$ & $(0.017)$ & $(0.021)$ \\
\hline \multirow[t]{2}{*}{ IV } & $0.566^{* * *}$ & 0.279 & 0.066 & 0.092 & 0.312 \\
\hline & $(0.188)$ & $(0.205)$ & $(0.194)$ & $(0.235)$ & $(0.274)$ \\
\hline Observations & 6,397 & 5,864 & 5,420 & 4,491 & 3,330 \\
\hline F statistic 1st Stage & 16.63 & 12.24 & 13.49 & 10.12 & 7.689 \\
\hline Hansen Test p-value & 0.612 & 0.962 & 0.424 & 0.552 & 0.164 \\
\hline \multicolumn{6}{|l|}{ First stage coefficients } \\
\hline \multirow[t]{2}{*}{ Friend/relative ill } & $0.136^{* * *}$ & $0.150^{* * *}$ & $0.146^{* * *}$ & $0.140^{* * *}$ & $0.138^{* * *}$ \\
\hline & $(0.031)$ & $(0.033)$ & $(0.035)$ & $(0.040)$ & $(0.032)$ \\
\hline \multirow[t]{2}{*}{ Friend/relative died } & 0.053 & 0.061 & 0.044 & 0.052 & $0.066^{*}$ \\
\hline & $(0.034)$ & $(0.037)$ & $(0.041)$ & $(0.046)$ & $(0.035)$ \\
\hline \multicolumn{6}{|c|}{ Panel b) Mental health at 8 weeks post birth } \\
\hline \multirow[t]{2}{*}{ OLS } & $0.278^{* * *}$ & $0.275^{* * *}$ & $0.262^{* * *}$ & $0.254^{* * *}$ & $0.214^{* * *}$ \\
\hline & $(0.015)$ & $(0.016)$ & $(0.016)$ & $(0.019)$ & $(0.024)$ \\
\hline \multirow[t]{2}{*}{ IV } & 0.244 & $0.359^{*}$ & $0.405^{*}$ & 0.254 & 0.175 \\
\hline & $(0.217)$ & $(0.210)$ & $(0.217)$ & $(0.261)$ & $(0.239)$ \\
\hline Observations & 6,209 & 5,694 & 5,274 & 4,374 & 3,253 \\
\hline F statistic 1st Stage & 11.02 & 11.65 & 11.16 & 8.387 & 10.32 \\
\hline Hansen Test p-value & 0.0396 & 0.00188 & 0.0547 & 0.306 & 0.911 \\
\hline \multicolumn{6}{|l|}{ First stage coefficients } \\
\hline \multirow[t]{2}{*}{ Friend/relative ill } & $0.057^{*}$ & $0.091^{* * *}$ & $0.102^{* * *}$ & $0.086^{* *}$ & $0.139^{* * *}$ \\
\hline & $(0.032)$ & $(0.033)$ & $(0.035)$ & $(0.037)$ & $(0.042)$ \\
\hline \multirow[t]{2}{*}{ Friend/relative died } & $0.138^{* * *}$ & $0.125^{* * *}$ & $0.119^{* * *}$ & $0.123^{* * *}$ & $0.125^{* * *}$ \\
\hline & $(0.035)$ & $(0.036)$ & $(0.038)$ & $(0.041)$ & $(0.047)$ \\
\hline
\end{tabular}

All regressions contain the set of controls listed in Table 4. 
Table 6

Effect of mothers' mental health on child cognitive outcomes

\begin{tabular}{|c|c|c|c|c|c|}
\hline Child age & $\begin{array}{c}(1) \\
\text { School } \\
\text { Assessment }\end{array}$ & $\begin{array}{c}(2) \\
\mathrm{KS} 1\end{array}$ & $\begin{array}{c}(3) \\
\mathrm{KS} 2\end{array}$ & $\begin{array}{c}(4) \\
\text { KS3 }\end{array}$ & $\begin{array}{c}(5) \\
\text { KS4 }\end{array}$ \\
\hline Age & 4 & 7 & 11 & 14 & 16 \\
\hline \multicolumn{6}{|c|}{ Panel a) Mental health at 18 weeks gestation } \\
\hline OLS & $\begin{array}{c}-0.053^{* * *} \\
(0.012)\end{array}$ & $\begin{array}{c}-0.041^{* * *} \\
(0.011)\end{array}$ & $\begin{array}{c}-0.048^{* * *} \\
(0.012)\end{array}$ & $\begin{array}{c}-0.063^{* * *} \\
(0.012)\end{array}$ & $\begin{array}{c}-0.059^{* * * *} \\
(0.011)\end{array}$ \\
\hline IV & $\begin{array}{c}0.094 \\
(0.180)\end{array}$ & $\begin{array}{c}0.012 \\
(0.162)\end{array}$ & $\begin{array}{l}-0.102 \\
(0.167)\end{array}$ & $\begin{array}{l}-0.024 \\
(0.180)\end{array}$ & $\begin{array}{l}-0.163 \\
(0.167)\end{array}$ \\
\hline Observations & 5,851 & 7,647 & 7,289 & 6,685 & 7,387 \\
\hline F statistic 1st Stage & 13.49 & 15.93 & 13.22 & 12.85 & 15.67 \\
\hline Hansen Test p-value & 0.253 & 0.845 & 0.163 & 0.350 & 0.785 \\
\hline \multicolumn{6}{|l|}{ First stage coefficients } \\
\hline Friend/relative ill & $\begin{array}{c}0.110^{* * *} \\
(0.029)\end{array}$ & $\begin{array}{c}0.116^{* * *} \\
(0.028)\end{array}$ & $\begin{array}{c}0.121^{* * *} \\
(0.026)\end{array}$ & $\begin{array}{c}0.106^{* *} \\
(0.041)\end{array}$ & $\begin{array}{c}0.115^{* * *} \\
(0.036)\end{array}$ \\
\hline Friend/relative died & $\begin{array}{c}0.088^{* * * *} \\
(0.033)\end{array}$ & $\begin{array}{c}0.091^{* * *} \\
(0.032)\end{array}$ & $\begin{array}{c}0.087^{* * *} \\
(0.030)\end{array}$ & $\begin{array}{c}0.034 \\
(0.047)\end{array}$ & $\begin{array}{l}0.074^{*} \\
(0.041)\end{array}$ \\
\hline \multicolumn{6}{|c|}{ Panel b) Mental health at 8 weeks post-birth } \\
\hline OLS & $\begin{array}{c}-0.043^{* * *} \\
(0.012)\end{array}$ & $\begin{array}{c}-0.046^{* * *} \\
(0.012)\end{array}$ & $\begin{array}{c}-0.033^{* * *} \\
(0.012)\end{array}$ & $\begin{array}{c}-0.042^{* * *} \\
(0.012)\end{array}$ & $\begin{array}{c}-0.033^{* * *} \\
(0.012)\end{array}$ \\
\hline IV & $\begin{array}{c}0.158 \\
(0.167)\end{array}$ & $\begin{array}{c}0.040 \\
(0.158)\end{array}$ & $\begin{array}{l}-0.022 \\
(0.161)\end{array}$ & $\begin{array}{c}0.149 \\
(0.172)\end{array}$ & $\begin{array}{c}0.255 \\
(0.168)\end{array}$ \\
\hline Observations & 5,572 & 7,282 & 6,934 & 6,359 & 7,030 \\
\hline F statistic 1st Stage & 14.22 & 16.09 & 14.04 & 12.45 & 16.15 \\
\hline Hansen Test p-value & 0.259 & 0.942 & 0.816 & 0.761 & 0.918 \\
\hline \multicolumn{6}{|l|}{ First stage coefficients } \\
\hline Friend/relative ill & $\begin{array}{c}0.173^{* * *} \\
(0.039)\end{array}$ & $\begin{array}{c}0.161^{* * *} \\
(0.034)\end{array}$ & $\begin{array}{c}0.149 * * * \\
(0.034)\end{array}$ & $\begin{array}{c}0.154^{* * *} \\
(0.036)\end{array}$ & $\begin{array}{c}0.160^{* * *} \\
(0.034)\end{array}$ \\
\hline Friend/relative died & $\begin{array}{l}0.066^{*} \\
(0.035)\end{array}$ & $\begin{array}{l}0.058^{*} \\
(0.030)\end{array}$ & $\begin{array}{c}0.063^{* *} \\
(0.031)\end{array}$ & $\begin{array}{c}0.050 \\
(0.033)\end{array}$ & $\begin{array}{c}0.066^{* *} \\
(0.031)\end{array}$ \\
\hline
\end{tabular}

All regressions contain the set of controls listed in Table 4. 


\section{Table 7}

Maternal mental health on post-birth parental investments

\begin{tabular}{|c|c|c|}
\hline Mothers' mental health & 18 weeks gestation & 8 weeks post birth \\
\hline Ever breastfed: 6 months & $\begin{array}{c}0.171 \\
(0.215)\end{array}$ & $\begin{array}{c}0.588^{* *} \\
(0.239)\end{array}$ \\
\hline Breastfed for $\geq 3$ months & $\begin{array}{c}0.052 \\
(0.090)\end{array}$ & $\begin{array}{l}0.162^{*} \\
(0.095)\end{array}$ \\
\hline Mother parenting score: 6 months & $\begin{array}{c}0.568 * * \\
(0.286)\end{array}$ & $\begin{array}{c}0.045 \\
(0.283)\end{array}$ \\
\hline Mother parenting score: 18 months & $\begin{array}{l}-0.300 \\
(0.540)\end{array}$ & $\begin{array}{c}-1.035^{*} \\
(0.595)\end{array}$ \\
\hline Mother parenting score: 24 months & $\begin{array}{c}0.482 \\
(0.464)\end{array}$ & $\begin{array}{c}0.756 \\
(0.612)\end{array}$ \\
\hline Mother parenting score: 38 months & $\begin{array}{c}0.377 \\
(0.543)\end{array}$ & $\begin{array}{l}-0.042 \\
(0.565)\end{array}$ \\
\hline Mother parenting score: 42 months & $\begin{array}{l}-0.207 \\
(0.832)\end{array}$ & $\begin{array}{l}-0.498 \\
(0.856)\end{array}$ \\
\hline Mother teaching score: 18 months & $\begin{array}{c}0.167 \\
(0.265)\end{array}$ & $\begin{array}{c}0.628 * * \\
(0.296)\end{array}$ \\
\hline Mother teaching score: 30 months & $\begin{array}{c}0.334 \\
(0.223)\end{array}$ & $\begin{array}{c}0.224 \\
(0.188)\end{array}$ \\
\hline Mother teaching score: 42 months & $\begin{array}{c}0.199 \\
(0.221)\end{array}$ & $\begin{array}{c}0.140 \\
(0.206)\end{array}$ \\
\hline Mother activity score: 6 months & $\begin{array}{c}0.328 \\
(0.500)\end{array}$ & $\begin{array}{c}0.075 \\
(0.491)\end{array}$ \\
\hline Mother activity score: 30 months & $\begin{array}{c}0.055 \\
(0.638)\end{array}$ & $\begin{array}{l}-0.038 \\
(0.538)\end{array}$ \\
\hline Mother activity score: 42 months & $\begin{array}{c}0.820 \\
(0.549)\end{array}$ & $\begin{array}{c}0.192 \\
(0.515)\end{array}$ \\
\hline Toy score: 24 months & $\begin{array}{c}2.209^{* * *} \\
(0.712)\end{array}$ & $\begin{array}{c}0.877 \\
(0.748)\end{array}$ \\
\hline Toy score: 42 months & $\begin{array}{c}0.018 \\
(0.117)\end{array}$ & $\begin{array}{c}0.026 \\
(0.116)\end{array}$ \\
\hline
\end{tabular}

Column (1) and (2) report the coefficient on mothers' mental health at 18 weeks gestation and 8 weeks post birth respectively, on each parental investment. Each element within a row and column represents a different regression with the dependent variable given by the parental investment. All regressions contain the set of controls listed in Table 4. Maternal mental health is instrumented in all regressions. 


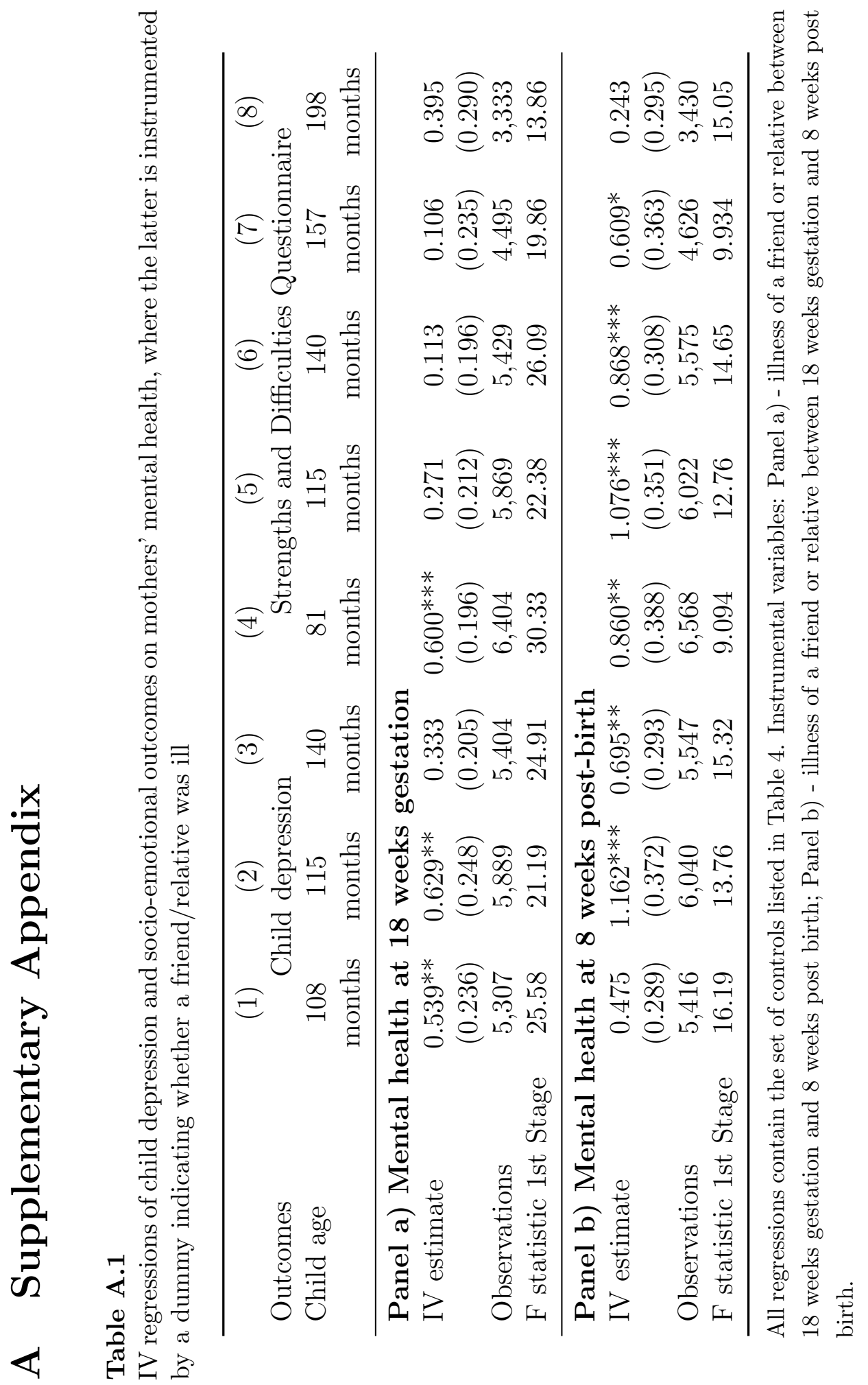




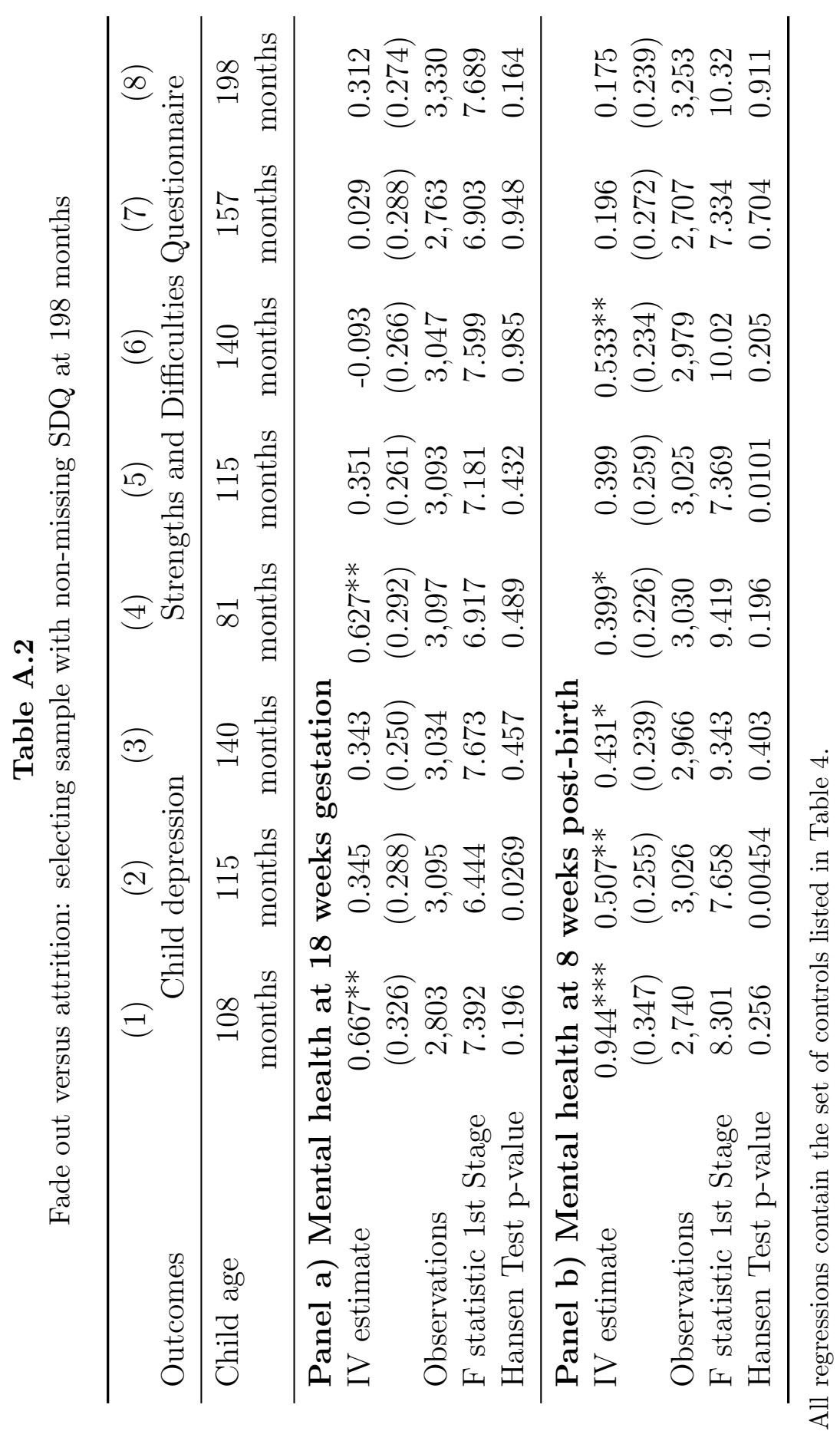




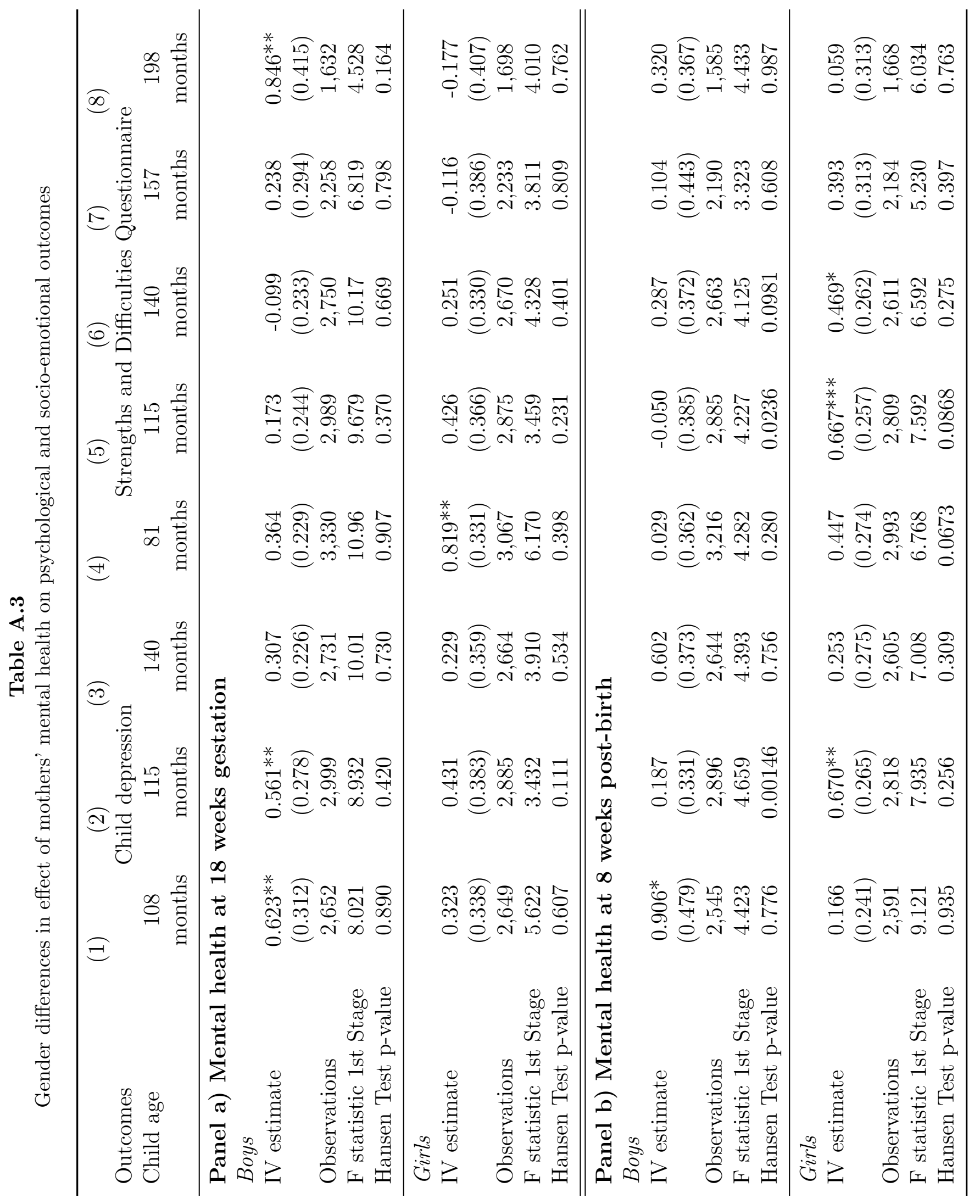


Table A.4

Gender differences in effect of mothers' mental health on cognitive outcomes

\begin{tabular}{lccccc}
\hline Outcomes & $\begin{array}{c}(1) \\
\text { School }\end{array}$ & $\begin{array}{c}(2) \\
\text { KS1 }\end{array}$ & $\begin{array}{c}(3) \\
\text { KS2 }\end{array}$ & $\begin{array}{c}(4) \\
\text { Assessment }\end{array}$ & $\begin{array}{c}(5) \\
\text { KS4 }\end{array}$ \\
Child age & 4 & 7 & 11 & 14 & 16 \\
\hline Panel a) Mental health at 18 weeks gestation & & \\
Boys & & & & & \\
IV estimate & 0.183 & 0.109 & -0.101 & 0.023 & 0.036 \\
& $(0.270)$ & $(0.236)$ & $(0.227)$ & $(0.277)$ & $(0.241)$ \\
Observations & 3,042 & 3,926 & 3,728 & 3,426 & 3,772 \\
F statistic 1st Stage & 6.715 & 7.975 & 7.196 & 5.637 & 6.930 \\
Hansen Test p-value & 0.533 & 0.873 & 0.241 & 0.557 & 0.923 \\
\hline Girls & & & & & \\
IV estimate & 0.007 & -0.102 & -0.115 & -0.085 & -0.339 \\
& $(0.238)$ & $(0.221)$ & $(0.244)$ & $(0.232)$ & $(0.235)$ \\
Observations & 2,809 & 3,721 & 3,561 & 3,259 & 3,615 \\
F statistic 1st Stage & 6.825 & 8.071 & 6.229 & 7.258 & 8.840 \\
Hansen Test p-value & 0.461 & 0.801 & 0.505 & 0.546 & 0.938 \\
\hline \hline
\end{tabular}

\begin{tabular}{lccccc}
\hline \hline Panel b) Mental health at 8 weeks post birth & & \\
Boys & & & & & \\
IV estimate & 0.401 & 0.132 & -0.144 & 0.001 & 0.108 \\
& $(0.300)$ & $(0.348)$ & $(0.351)$ & $(0.388)$ & $(0.319)$ \\
Observations & 2,892 & 3,730 & 3,538 & 3,250 & 3,581 \\
F statistic 1st Stage & 5.392 & 3.792 & 3.139 & 2.363 & 3.897 \\
Hansen Test p-value & 0.0829 & 0.342 & 0.668 & 0.401 & 0.304 \\
\hline Girls & & & & & \\
IV estimate & -0.113 & -0.043 & 0.012 & 0.111 & 0.267 \\
& $(0.197)$ & $(0.163)$ & $(0.167)$ & $(0.164)$ & $(0.184)$ \\
Observations & 2,680 & 3,552 & 3,396 & 3,109 & 3,449 \\
F statistic 1st Stage & 8.927 & 13.35 & 12.55 & 12.91 & 13.62 \\
Hansen Test p-value & 0.945 & 0.388 & 0.826 & 0.670 & 0.251 \\
\hline
\end{tabular}




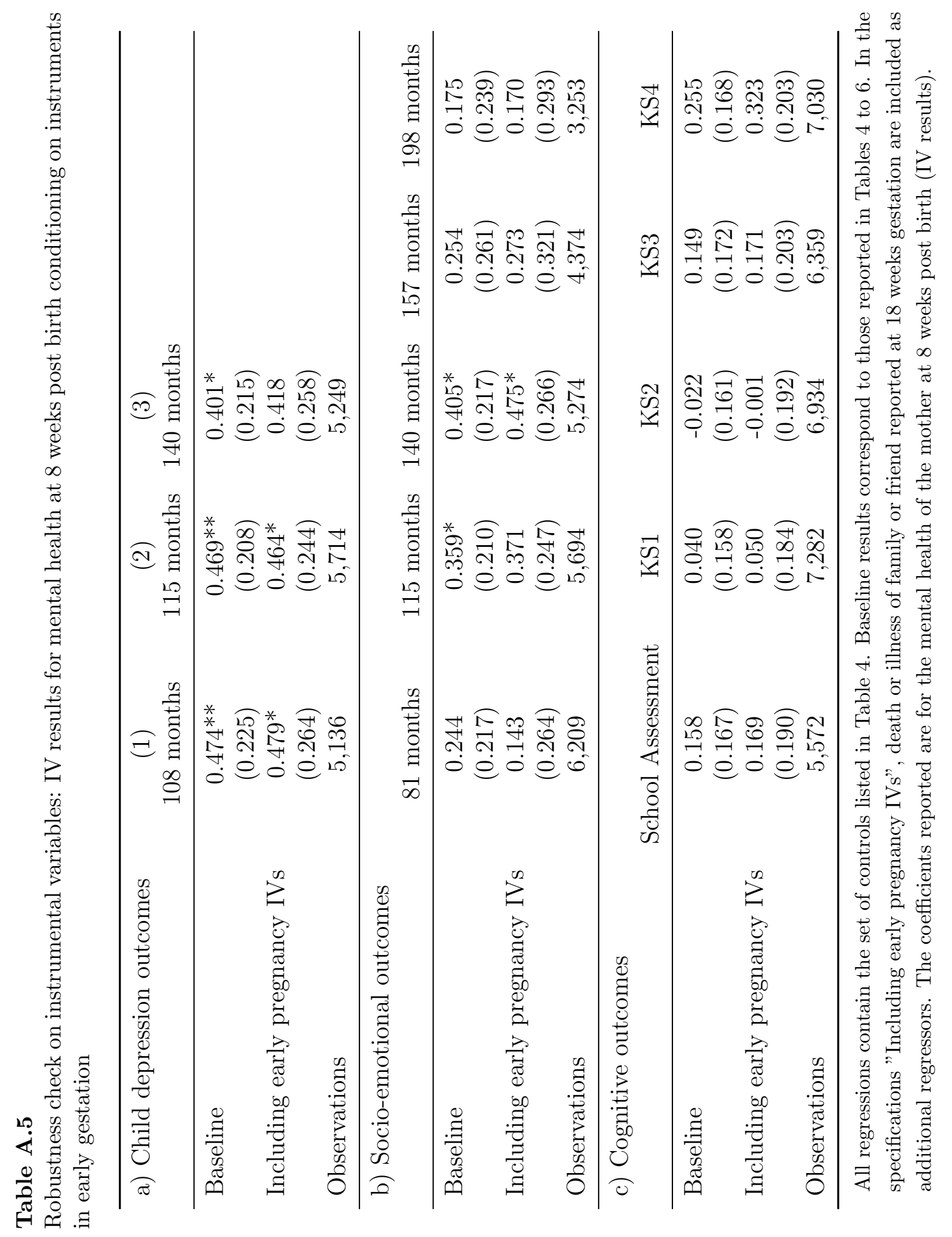




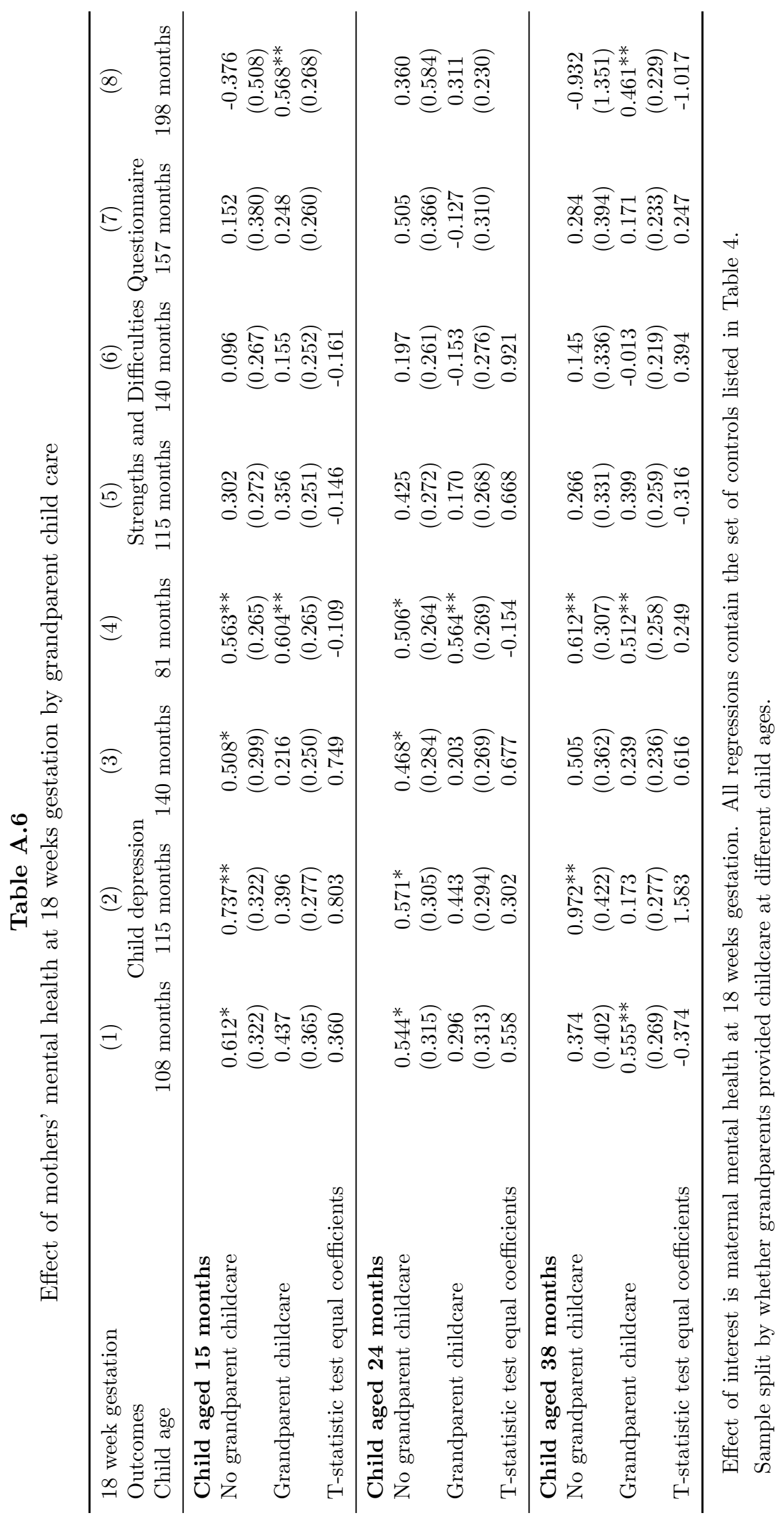




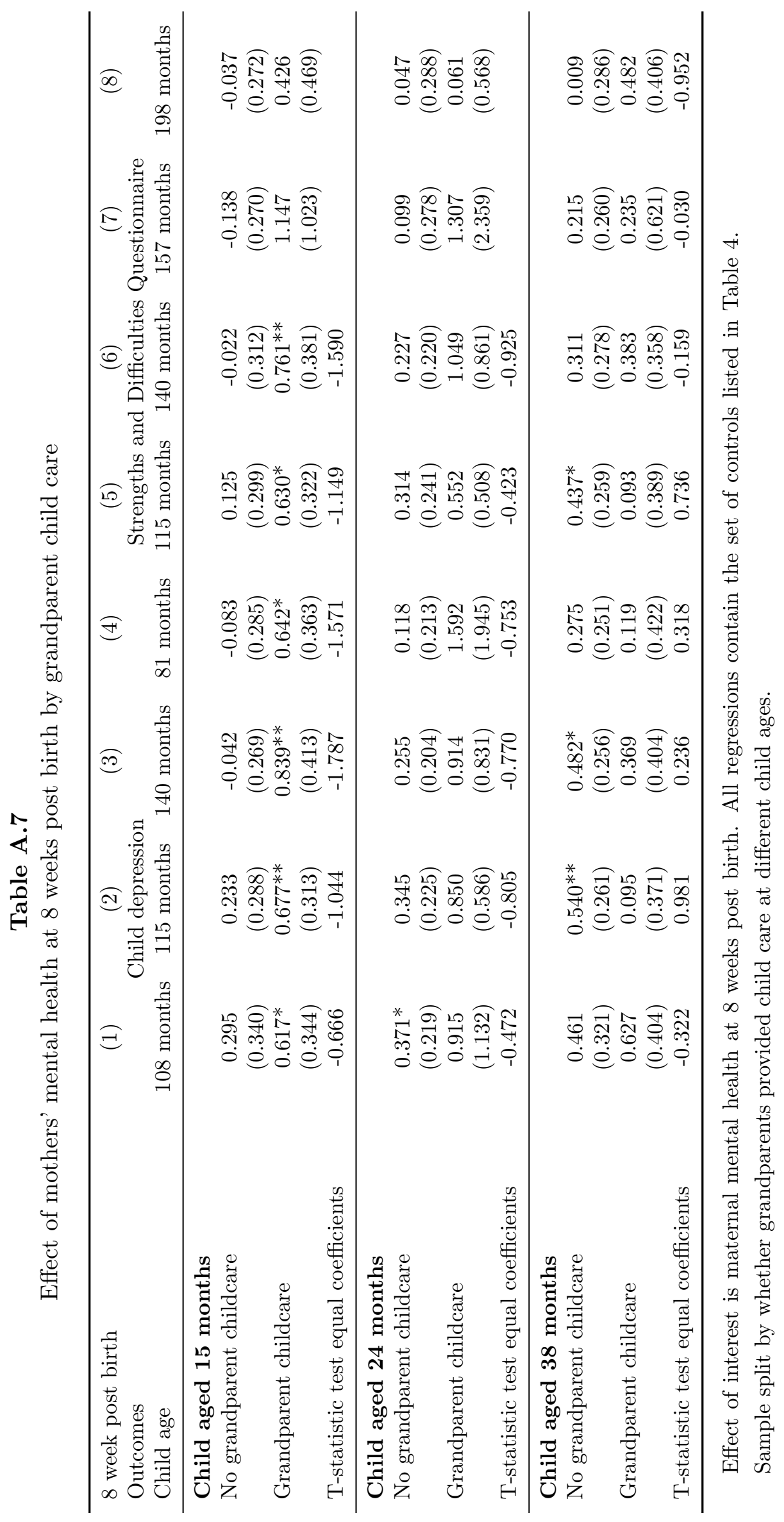


Table A.8

Descriptive statistics on parental investment measures

\begin{tabular}{lccc}
\hline & $\mathrm{N}$ & Mean & Standard Deviation \\
\hline Parental investments & & & \\
Ever breastfed: 6 months & 7,632 & 0.627 & 0.484 \\
Breastfed for $\geq 3$ months & 7,632 & 0.467 & 0.499 \\
Mother parenting score: 6 months & 7,784 & 10.504 & 1.479 \\
Mother parenting score: 18 months & 7,401 & 32.430 & 3.337 \\
Mother parenting score: 24 months & 6,978 & 34.541 & 2.635 \\
Mother parenting score: 38 months & 7,117 & 25.229 & 2.958 \\
Mother parenting score: 42 months & 7,085 & 28.665 & 4.733 \\
Mother teaching score: 18 months & 7,584 & 8.038 & 1.561 \\
Mother teaching score: 30 months & 7,146 & 6.649 & 1.052 \\
Mother teaching score: 42 months & 7,082 & 6.952 & 1.157 \\
Mother activity score: 6 months & 7,789 & 14.379 & 2.615 \\
Mother activity score: 30 months & 7,197 & 18.503 & 3.041 \\
Mother activity score: 42 months & 7,077 & 18.691 & 2.865 \\
Toy score: 24 months & 6,965 & 23.466 & 3.334 \\
Toy score: 42 months & 7,082 & 8.164 & 0.650 \\
\hline
\end{tabular}


Table A.9

Components of parental investment scores

\begin{tabular}{|c|c|c|c|c|c|c|}
\hline Parenting score & $6 \mathrm{~m}$ & $18 \mathrm{~m}$ & $24 \mathrm{~m}$ & $30 \mathrm{~m}$ & $38 \mathrm{~m}$ & $42 \mathrm{~m}$ \\
\hline Mother plays with child & $\mathrm{X}$ & & & & & \\
\hline Mother sings to child & $\mathrm{X}$ & $\mathrm{X}$ & $\mathrm{X}$ & & $\mathrm{X}$ & $\mathrm{X}$ \\
\hline Mother plays with toys with child & $\mathrm{X}$ & $\mathrm{X}$ & & & $\mathrm{X}$ & $\mathrm{X}$ \\
\hline Mother cuddles child & $\mathrm{X}$ & $\mathrm{X}$ & $\mathrm{X}$ & & $\mathrm{X}$ & $\mathrm{X}$ \\
\hline Mother does physical play (e.g. clapping, rolling over) & $\mathrm{X}$ & $\mathrm{X}$ & & & $\mathrm{X}$ & $\mathrm{X}$ \\
\hline Mother takes child for walks & $\mathrm{X}$ & $\mathrm{X}$ & & & $\mathrm{X}$ & $\mathrm{X}$ \\
\hline Mother baths child & & $\mathrm{X}$ & & & & \\
\hline Mother feeds child & & $\mathrm{X}$ & & & $\mathrm{X}$ & $\mathrm{X}$ \\
\hline Mother reads stories to child & & $\mathrm{X}$ & $\mathrm{X}$ & & $\mathrm{X}$ & $\mathrm{X}$ \\
\hline Mother lets child play with paint/mud/messy objects & & & $\mathrm{X}$ & & & \\
\hline Mother lets child build towers & & & $\mathrm{X}$ & & & \\
\hline Mother praises child & & & $\mathrm{X}$ & & & \\
\hline Mother shouts at child & & & $\mathrm{X}$ & & & \\
\hline Mother slaps child & & & $\mathrm{X}$ & & & \\
\hline Mother and child have meals together & & & $\mathrm{X}$ & & & \\
\hline Mother lets child make noise & & & $\mathrm{X}$ & & & \\
\hline Mother baths child & & & & & $\mathrm{X}$ & $\mathrm{X}$ \\
\hline Mother puts child to bed & & & & & $\mathrm{X}$ & $\mathrm{X}$ \\
\hline \multicolumn{7}{|l|}{ Teaching score } \\
\hline Mum teaches child clapping games & & $\mathrm{X}$ & & & & \\
\hline Mum teaches child names of body parts & & $\mathrm{X}$ & & & & \\
\hline Mum teaches child waving good bye & & $\mathrm{X}$ & & & & \\
\hline Mum teaches child colours & & $\mathrm{X}$ & & $\mathrm{X}$ & & $\mathrm{X}$ \\
\hline Mum teaches child alphabet & & $\mathrm{X}$ & & $\mathrm{X}$ & & $\mathrm{X}$ \\
\hline Mum teaches child numbers & & $\mathrm{X}$ & & $\mathrm{X}$ & & $\mathrm{X}$ \\
\hline Mum teaches child nursery rhymes & & $\mathrm{X}$ & & $\mathrm{X}$ & & $\mathrm{X}$ \\
\hline Mum teaches child songs & & $\mathrm{X}$ & & $\mathrm{X}$ & & $\mathrm{X}$ \\
\hline Mum teaches child shapes \& sizes & & $\mathrm{X}$ & & $\mathrm{X}$ & & $\mathrm{X}$ \\
\hline Mum teaches child politeness & & $\mathrm{X}$ & & $\mathrm{X}$ & & $\mathrm{X}$ \\
\hline \multicolumn{7}{|l|}{ Activity score } \\
\hline Mum takes child to local shops & $\mathrm{X}$ & & & $\mathrm{X}$ & & $\mathrm{X}$ \\
\hline Mum takes child to department store & $\mathrm{X}$ & & & $\mathrm{X}$ & & $\mathrm{X}$ \\
\hline Mum takes child to supermarket & $\mathrm{X}$ & & & $\mathrm{X}$ & & $\mathrm{X}$ \\
\hline Mum takes child to park or playground & $\mathrm{X}$ & & & $\mathrm{X}$ & & $\mathrm{X}$ \\
\hline Mum takes child to visit friends/family & $\mathrm{X}$ & & & $\mathrm{X}$ & & $\mathrm{X}$ \\
\hline Mum takes child to library & & & & $\mathrm{X}$ & & $\mathrm{X}$ \\
\hline Mum takes child to places of interest (e.g. zoo) & & & & $\mathrm{X}$ & & $\mathrm{X}$ \\
\hline Mum takes child to places of entertainment (e.g. funfair) & & & & $\mathrm{X}$ & & $\mathrm{X}$ \\
\hline \multicolumn{7}{|l|}{ Toy score } \\
\hline Child has cuddly toys & & & $\mathrm{X}$ & & & $\mathrm{X}$ \\
\hline Child has dolls & & & $\mathrm{X}$ & & & \\
\hline Child has a swing & & & $\mathrm{X}$ & & & \\
\hline Child has toy cars/lorries & & & $\mathrm{X}$ & & & \\
\hline Child has jigsaw puzzles & & & $\mathrm{X}$ & & & $\mathrm{X}$ \\
\hline Child has mobiles & & & $\mathrm{X}$ & & & \\
\hline Child has construction toys & & & $\mathrm{X}$ & & & $\mathrm{X}$ \\
\hline Child has books & & & $\mathrm{X}$ & & & $\mathrm{X}$ \\
\hline Child has balls & & & $\mathrm{X}$ & & & \\
\hline Child has a walker (to push) & & & $\mathrm{X}$ & & & \\
\hline Child has a walker (to sit in) & & & $\mathrm{X}$ & & & \\
\hline Child has toys where (s)he has to fit things together & & & $\mathrm{X}$ & & & \\
\hline Child has push or pull toys & & & & & & $\mathrm{X}$ \\
\hline Child has co-ordination toys & & & & & & $\mathrm{X}$ \\
\hline Child has computer games & & & & & & $\mathrm{X}$ \\
\hline
\end{tabular}

